1988

\title{
Matter of Voice and Plot: Belief and Suspicion in Legal Storytelling, A
}

Richard K. Sherwin

New York Law School

Follow this and additional works at: http://digitalcommons.nyls.edu/fac_articles_chapters

\section{Recommended Citation}

87 Mich. L. Rev. 543 (1988-1989)

This Article is brought to you for free and open access by the Faculty Scholarship at DigitalCommons@NYLS. It has been accepted for inclusion in Articles \& Chapters by an authorized administrator of DigitalCommons@NYLS. 


\title{
A MATTER OF VOICE AND PLOT: BELIEF AND SUSPICION IN LEGAL STORYTELLING
}

\author{
Richard K. Sherwin*
}

[And one day the Muses of Olympus, daughters of Zeus, taught Hesiod glorious song; and this word first the goddesses said: W]e know how to speak many false things as though they were true; but we know, when we will, to utter true things.

- Hesiod

They said, "You have a blue guitar,

You do not play things as they are."

The man replied, "Things as they are

Are changed upon the blue guitar."

- Wallace Stevens

If we can get our voice right - our sense of self, language, and audience

- all else that matters will follow more surely than we can ever seek to compel it.

- James Boyd White

[But our problem today is] ... that we are in a state of great confusion and uncertainty (some might even say chaos) about what norms or "universals" ought to govern our practical lives.

- Richard Bernstein

\section{INTRODUCTION}

Amidst the current clamor of debate between critical "deconstructivists" on the one hand ${ }^{1}$ and liberal defenders on the other, ${ }^{2}$ a note of

* Assistant Professor of Law, New York Law School. B.A. 1975, Brandeis University; J.D. 1981, Boston College; L.L.M. 1985, Columbia University. - Ed. I wish to thank Bruce Ackerman, Neal Feigenson, Andrzej Rapaczynski, and Dr. Gilda Sherwin for their valuable comments on an earlier draft of this work. I would like to express special thanks to James Boyd White for his close reading of the text and his edifying responses to it. Finally, I wish to express my gratitude to the editors of the Review for stimulating and enriching my own interpretive critique of the article. Responsibility for distortions or mystifications that remain are mine - and the reader's for finding them.

1. The scholars in this group, loosely gathered under the rubric of Critical Legal Studies, reflect diversified interests and perspectives. A common theme among many of them, however, focuses upon the contradictions that allegedly lie at the heart of liberal theory (e.g., between "neutral" principles and "subjective" preferences, reason and desire, facts and theory). See, e.g., R. Unger, KNowledge and Politics (1975); R. Unger, LAW IN MOdern SOCieTy: TOWARD A CRITICISM OF SocIal Theory (1976); Kennedy, Form and Substance in Private Law Adjudication, 89 HARv. L. Rev. 1685 (1976); Tushnet, Critical Legal Studies and Constitutional Law: An Essay in Deconstruction, 36 STAN. L. REV. 623 (1984).

2. Defenders of liberal theory also reflect a broad spectrum of beliefs, including faith in the stabilizing and legitimating force of "neutral principles," see Wechsler, Toward Neutral Principles of Constitutional Law, 73 HARV. L. REV. 1 (1959); B. ACKERMAN, Social JuSTICE IN THE 
calm can be heard. It may not be loud, but it is clear and steady; and there are signs that it is growing stronger. The note I refer to derives, to a significant extent, from an ancient but recently revitalized source; it sounds within the realm of rhetoric. ${ }^{3}$

In this article $I$ attempt to show that an enhanced awareness of the rhetorical perspective toward $\mathrm{law}^{4}$ is a good thing for the legal culture. Indeed, I contend that its affirmation of the interpretive process provides a secure point of departure for legal discourse and debate among legal scholars, decisionmakers, and practitioners. ${ }^{5}$ However, while the affirmative message that this perspective brings may be desirable (at least to those who remain committed to the project of liberalism), 6 .

LiBERAL STATE 10-12, 356-71 (1980); support for the "government structure in general, and the system of checks and balances in particular ...," see Carter, Constitutional Adjudication and the Indeterminate Text: A Preliminary Defense of an Imperfect Muddle, 94 YALE L.J. 821, 824 (1985); see also A. BICKel, The LeAst DANGerous BRANCH (2d ed. 1986); and a conceptualization of "law as integrity," which views law as a "chain" of "interpretive concepts," or as a system that encompasses a "coherent set of principles about people's rights and duties," see R. DWORKIN, LAW'S EMPIRE 176-224, 255-58, 410-13 (1986).

3. The classic definition of rhetoric comes from Aristotle: "Rhetoric may be defined as the faculty of observing in any given case the available means of persuasion." ARISTOTLE, in ARISTOTLE: Rhetoric AND Politics 24 (W. Rhys Roberts trans. 1954). See also Isocrates, Antidosis, in 2 Isocrates 327 (G. Norlin trans. 1968):

[B]ecause there has been implanted in us the power to persuade each other and to make clear to each other whatever we desire, not only have we escaped the life of wild beasts, but we have come together and founded cities and made laws and invented arts; and, generally speaking, there is no institution devised by man which the power of speech has not helped us to establish.

For a more recent statement on rhetoric, see McKeon, 17 Dialogue and Controversy in Philosophy, in Philosophy and Phenomenological Research 143, 162 (1956) (noting that the fundamental assumptions of the rhetorical tradition are that "knowledge is advanced best by the free opposition of arguments, that a common truth may be given a variety of statements from different perspectives, and that there is an element of truth in all philosophic positions").

4. This approach may also be described as the turn toward interpretation, or "hermeneutics." See Minow, Interpreting Rights: An Essay for Robert Cover, 96 YALE L.J. 1860, 1860-62 \& n.3 (1987); Cover, Violence and the Word, 95 YALE L.J. 1601, n.2 (1986); see also Sherwin, Dialects and Dominance: A Study of Rhetorical Fields in the Law of Confessions, 136 U. PA. L. REv. 729 (1988); Burt, Constitutional Law and the Teaching of Parables, 93 YALE L.J. 455, 48690 (1984).

5. Writers who have played a leading role in reaffirming the rhetorical perspective include Chaim Perelman and James Boyd White. See C. Perelman, The New Rhetoric: A Treatise on Argumentation (1969); C. Perelman, The Realm of Rhetoric (W. Kluback trans. 1982); J.B. WhITE, WHEN WORDS Lose TheIR MEANING (1984); J.B. White, HeRACLES' BOW: ESSAys ON THE RHETORIC AND POETICS OF THE LAW (1985).

6. The exact nature of the liberal project escapes easy encapsulation. Indeed, that liberalism means different things to different people is readily apparent from the works of such liberal defenders as Ackerman, Dworkin, von Hayek, Nozick, and Rawls. For those with a taste for definitions, however, consider Guido de Ruggiero's:

In its larger sense liberalism is a deep lying mental attitude which attempts in the light of its presuppositions to analyze and integrate the varied intellectual, moral, religious, social, economic and political relationships of human society. Its primary postulate, the spiritual freedom of mankind, not only repudiates naturalistic or deterministic interpretations of human action but posits a free individual conscious of his capacity for unfettered development and self-expression. It follows therefore as an obvious corollary in the grammar of liberalism that any attempt on the part of constituted authorities to exert artificial pressure or regula- 
there is reason yet to be wary. For as history teaches, desire has a way of outstripping reality - sometimes with disastrous consequences. ${ }^{7}$ Providing a clearer understanding of the caveat that must accompany the rhetorical (or interpretive) turn in the legal culture is one of the goals this article seeks to achieve. ${ }^{8}$

In what follows, I describe legal rhetoricians as individuals who are enchanted, and who seek to enchant others, by language. ${ }^{9}$ For them, the reality of textual or discursive meaning is a given, and the struggle to articulate persuasive interpretations, for all its difficulties, presents no threat to the advent of meaning itself. Indeed, the interpreter's at times Herculean efforts in support of textual meaning bear witness to the strength of her belief. To be sure, the nature of that belief may vary. Yet, whether it holds that meaning can be unpacked from the words of the text, ${ }^{10}$ or from the text-maker's intentions or purposes, ${ }^{11}$ or from the effect the text has upon the reader, ${ }^{12}$ or from

tion on the individual, in his inner and outer adjustments, is an unjustifiable interference, a stultification of his personality and initiative. Against such coercive interference, whether in the moral, the religious, the intellectual, the social, the economic or the political sphere, liberalism has consistently arrayed its forces.

E. Seligman \& A. Johnson, The Encyclopedia of the Social Sciences 435 (1933). For an excellent study of liberalism's roots in the modern. political philosophies of Hobbes, Locke, and Rousseau, see A. RAPACZYNSKI, NATURE AND Politics (1987).

7. Recall that it was the utopian desire to establish the perfect socialist state that impelled revolutionary leaders to commit genocide in Kampuchea. Nor can we-easily forget that it was a similarly utopian desire that impelled National Socialist leaders to commit genocide in their effort to purify the race. Cf. A. CAMUS, THE REBEL 208 (1956) ("Utopia replaces God by the future. Then it proceeds to identify the future with ethics; the only values are those which serve this particular future. For that reason Utopias have almost always been coercive and authoritarian.").

8. Robert Cover's last two essays follow a similarly cautionary line. See Cover, supra note 4; Cover, The Bonds of Constitutional Interpretation: Of the Word, the Deed, and the Role, $20 \mathrm{GA}$. L. REV. 815 (1986).

9. See generally Vining, Law and Enchantment, 86 MiCH. L. REV. 577 (1987).

10. See, e.g., J. ELY, DEMOCRACY AND DISTRUST 1-41 (1980) (describing the text-dependency of judicial outcomes or decisions as "clause-bound interpretivism"); see also Graves v. New York, 206 U.S. 466, 491-92 (1939) ("[T]he ultimate touchstone of constitutionality is the Constitution itself and not what we have said about it.").

11. See, e.g., Monaghan, Our Perfect Constitution, 56 N.Y.U. L. REv. 353, 374-75 (1981) ("All law, the constitution not excepted, is a purposive ordering of norms. Textual language embodies one or more purposes, and the text may be understood and usefully applied only if its purposes are understood. No convincing reason appears why purpose may be ascertained from any relevant source, including its 'legislative history'."); see also United States v. American Trucking Assn., 310 U.S. 534, 543 (1940) ("There is, of course, no more persuasive evidence of the purpose of a [statutory text] than the words by which the legislature undertook to give expression to its wishes.").

12. See, e.g., Weisberg, Text into Theory: A Literary Approach to the Constitution, $20 \mathrm{GA}$. L. REv. 939, $951-54$ (1986) (describing the American post-structural school of "reader-response" criticism). Stanley Fish also expresses this view of the text:

[D]ifferent notions of what it is to read . . . are finally different notions of what it is to be human. In [one] view, the world, or the world of the text, is already ordered and filled with significances and what the reader is required to do to get them out (hence, the question, "What did you get out of that?"). In short, the reader's job is to extract the meanings that 
the "fusion of horizons" that occurs between textmaker and reader thereby integrating the "prejudices" of each within a single interpretive act ${ }^{13}$ - the rhetorician's faith in meaning nevertheless remains. I call this faith "rhetorical affirmation."

In contrast to the rhetorical affirmer, however, there are those who play down or deny altogether the possibilities of discursive or textual meaning. To some within this group, it is a question of understanding the social goal that the text realizes in practice, independent of the words that a particular textmaker may use. ${ }^{14}$ Others, taking this skeptical insight a step further, view the text as a disguise or a distraction. For them, the surface of the text must be broken before deliberately hidden or unconsciously concealed subtexts can lead us to the textmaker's underlying (possibly irrational) desires or subjective preferences. ${ }^{15}$ On this view, once the text's pretensions of meaning have been pierced, its unuttered significance - in the form of instrumental manipulations or self-serving power-plays - may enter the light of critical reflection.

For those who would have us break with the past, the challenge of

formal patterns possess prior to and independently of, his activities. In my view, these same activities are constitutive of a structure of concerns which is necessarily prior to any examination of meaningful patterns because it is itself the occasion of their coming into being.

S. Fish, Is There a TeXT IN This Class? 94 (1980).

13. See, e.g., H. Gadamer, Philosophical Hermeneutics 64 (1976) ("We are always already biased in our thinking and knowing by our linguistic interpretation of the world. To grow into this linguistic interpretation means to grow up in the world."). Gadamer also notes, however, that while individual biases necessarily define the horizon of our understanding, we can enter into relationship with the other - fuse our own limited horizon with the one the text holds out - through self-reflective interpretation. See H. GADAMER, TRUTH AND METHOD 358 (1975) ("To interpret means precisely to use one's own preconceptions so that the meaning of the text can really be made to speak for us.").

14. This perspective informed much of the writings of those associated with the American Legal Realist movement. Karl Llewellyn, for example, wrote:

What realism was, and is, is a method, nothing more, and the only tenet involved is that the method is a good one. "See it fresh," "See it as it works" - that was to be the foundation of any solid work, to any end. From there, one goes into inquiry about, e.g., What-it-is-for (function or goal), or, e.g., to build a judgment on how far the measure fits the purpose, or, e.g., on how far the particular purpose harmonizes with the Good Life, or, e.g., on whether we do not then have to reexamine the original data about "How it has been working" - a matter which often answers very differently to different questions.

K. Llewellyn, The Common LAW TRAdition 510 (1960).

15. This view reflects the Critical Legal Studies movement's deepening of Legal Realist skepticism. See, e.g., Caudill, Disclosing Tilt: A Partial Defense of Critical Legal Studies and a Comparative Introduction to the Philosophy of the Law-Idea, 72 IowA L. REv. 287, 295 (1987) (viewing CLS scholarship as "a maturation of Realist methodologies in which (i) the new scholars disclose incoherencies using the methods of social or political theory, and (ii) the goal is a radical political agenda, not simply reformist policy programs") (footnote omitted); see also Kelman, Interpretive Construction in the Substantive Criminal Law, 33 STAN. L. REv. 591, 671 (1981) (disclosing unexplained and unjustified interpretive frameworks within the body of criminal law which serve to stabilize class domination or simply act as the "inexplicably unpatterned mediators of experience, the inevitably nonrational filters we need to be able to perceive or talk at all"). 
the moment is to show that the traditional interpretive practice (of reading and applying or distinguishing inherited texts) is both misguided and useless. Unless or until those in positions of power within the legal culture can be made to see the deceptions, the futility, or the irrationality of inherited doctrine or of traditional interpretive practice, inherited texts will undoubtedly continue to play an important role within the judicial decisionmaking process. The critic's task, therefore, is to disenchant the affirmers, to break the spell of belief in inherited meanings. The method of deconstruction, as practiced by members of the Critical Legal Studies movement, is the vehicle by which these critics have taken up the challenge to the liberal tradition. Their pivotal insight says that one cannot be enchanted by that which has come to be seen as illusion. By applying disillusioning critiques to doctrine, and to the process of interpretation itself, the critics would have us turn away from the past. I call these advocates of change "deconners" to remind the reader that the critic's deconstructions function as forms of disenchantment. ${ }^{16}$

In this text, I shall use James Boyd White's recent work on "constitutive rhetoric" as a vehicle for analyzing the tension described above between the deconstructivist's defiance of inherited texts or beliefs, on the one hand, and the rhetorician's faith in the meaningfulness of textual interpretations, on the other. According to White, "constitutive rhetoric" is

a set of resources for claiming, resisting, and declaring significance. It is a way of asking and responding to questions; of defining roles and positions from which, and voices with which, to speak; of creating and maintaining relations; of justifying and explaining action and inaction. It is one of the forms in which a culture lives and changes, drawing connections in special ways between past and present, near and far. The law ... is a system of meaning; it is a language and should be evaluated as such. ${ }^{17}$

By concentrating in this way upon the constructive aspect of tradi-

16. As we shall soon see, for some deconners demystification may appear as a triumph of reason. See infra notes 23 \& 29-30 and accompanying text. For others, however, the process of disenchantment serves as an end in itself; it provides a means of emancipation from the "false necessity" of inherited beliefs and social institutions. See infra note 44 and accompanying text.

In a sense, the deconners - like Conan Doyle's Sherlock Holmes, or that nonfictional detective of the psyche, Sigmund Freud - make their way in the world by revealing plots and subplots; they resolve textual mystifications by revealing the other's communicative distortions. See generally P. BRoOKs, ReAding for the Plot (1984).

17. J.B. White, Heracles' Bow, supra note 5, at 205. This rhetorical approach parallels what Cover describes as a "jurisgenesis," "the creation of legal meaning," or as building up a "nomos" or "normative universe." See Cover, The Supreme Court, 1982 Term - Foreword: Nomos and Narrative, 97 HARV. L. REV. 4-5, 11 (1983) ("No set of legal institutions or prescriptions exists apart from the narratives that locate it and give it meaning. For every constitution there is an epic, for each decalogue a scripture. Orice understood in the context of the narratives 
tional rhetorical practice, White brings a strongly affirmative voice to the legal culture. By failing to confront its negative aspects, however, White exposes his view to serious criticism. ${ }^{18}$ The danger here is that what is of value in White's work may be overshadowed by its limitations. I wish to shore up White's view by identifying at least some of its limitations and the dangers these limitations present to the legal culture. The essential point may be expressed as follows. While timely, and in large part worthy of praise, White's effort nevertheless reflects an overreaction against theory. To be sure, White is never explicit about whether it is theory in general, or only particular kinds of theorizing, which he finds objectionable. However, there is good reason to believe that his position embraces a fundamental antipathy toward the highly conceptual view of language that, according to White, theory in general entails. ${ }^{19}$

White works hard to curtail what he perceives as excessive schol-

that give it meaning, law becomes not merely a system of rules to be observed, but a world in which we live." (footnotes omitted)).

Notably, Dworkin's analysis of interpretive practice diverges from the rhetorical perspective of Perelman, White, Cover and myself, by virtue of its insistence upon making strong epistemological claims regarding comprehensive principles. See, e.g., R. DWORKIN, TAKING RIGHTS SERIOUSLY 87-88 (1977) (recommending a view of judicial decisionmaking that aspires to an "articulate consistency," a way of deciding cases that links a judge's most recent decision to "some comprehensive theory of general principles and policies that is consistent with other decisions also thought right"); R. DworkIN, supra note 2, at 219; see also B. ACKERMAN, PRIVATE PROPERTY AND THE CONSTITUTION 10-11 (1977) (describing "scientific policymaking" as the systematic application of a "comprehensive view"); $c f$. J.B. WHITE, WHEN WORDS LOSE THEIR MEANING, supra note 5, at 270 ("The task of the lawyer is not simply to persuade, using whatever cultural devices lie at hand, but to persuade a judge or jury that one result or another is the best way to act in the cultural situation defined by these facts or this evidence and by this set of statutes and opinions and understandings.").

18. See, e.g., Malkan, Law on a Darkling Plain (Book Review), 101 HARV. L. REV. 702, 706 (1988) ("White warns us that the stories we believe about ourselves have the potential to determine who we are, and he teaches us how to distinguish well-told from poorly told stories. White gives us little guidance, however, about how to distinguish a true story from a false one."); see also Weisberg, Law and Rhetoric (Book Review), 85 MicH. L. REV. 920, 922 (1987) ("[White's] assertion that law is rhetoric seems more intuitively accurate than, say, the view that law is science or economics. But his defense of legal rhetoric finally lacks the two elements provided by both traditional jurisprudence and the social sciences: a normative scale on which to judge legal behavior and a forthright analysis of such behavior as it is in fact practiced.").

19. See, e.g., J.B. WHITE, HERACLES' Bow, supra note 5:

I think that many academics in both law and literature have become rather too preoccupied with questions of "theory," and in so doing have committed themselves to a language and a set of practices, modeled perhaps on certain social sciences or on analytic philosophy, which actually cut them off from their greatest resource, the roots of their discipline in ordinary language and ordinary life.

Id. at $\mathrm{x}$ n.1.

On the other hand, when it takes specific form, White's criticism tends to focus upon one type of theorizing in particular: the utilitarian model of instrumental cost/benefit analysis. See, e.g., id. at 194-95. The domain of liberal theory is of course much broader than this. Compare, for example, the economic approach in R. POSNER, ECONOMIC ANALYSIS OF LAW (3d ed. 1986), and R. EPSTEIN, A THEORY OF STRICT Liability: TOWARD A REFormulation OF TORT LAW (1980), with the Kantian-oriented approach in Fletcher, Why Kant, 87 CoLUM. L. REV. 
arly indulgence in "conceptualistic" thinking. Along the way, however, he tends to overlook both the positive contribution that abstract or critical theory can make within the legal culture, and the inability of rhetoric to make up for its absence. As a corrective measure, I propose that the relationship between critical theory and affirmative rhetoric is not one of mutual exclusion, or even of separation; rather, the proper relationship is in the nature of a dialectic. ${ }^{20}$

421 (1987), and Rawls, Kantian Constructivism in Moral Theory, 77 J. PHIL. 515 (1980), or with the "dialogue" theory of liberal democracy in B. ACKERMAN, supra note 2.

Nor does liberal theorizing exhaust the field. For example, the writings of various members of the Critical Legal Studies movement reflect the influence of the critical theory of the Frankfurt School. See, e.g., Brosnan, Serious but Not Critical, 60 S. CAL. L. Rev. 259, 332-43 (1987), and Boyle, The Politics of Reason: Critical Legal Theory and Local Social Thought, 133 U. PA. L. REV. 685, 697-705 (1985). In broad strokes, "critical theory" in this context may be described as "a theory of the contemporary epoch that is guided by an interest in the future, that is, by an interest in the realization of a truly rational society in which men make their own history with will and consciousness." J. HABERMAS, LEGITIMATION CRISIS xi (1975) (from the introduction by T. McCarthy). See also G. Friedman, The-Political PhIlosophy of the Frankfurt ScHOOL (1981).

Ironically, the Frankfurt School critics are allies of White in their joint opposition to "scientistic" conceptualization or "technocratic consciousness," and to the rule of instrumental reason (what White refers to as "the mechanical and instrumental language of systems design and cost benefit-analysis," J.B. WHITE, supra at 195), at the expense of ethics as a category of life. See J. HABERMAS, LegITIMATION CRISIS, supra at xxi.

20. Following Ricoeur, the kind of abstract, systematizing, or "speculative" discourse which White opposes may be described as

the discourse that establishes the primary notions, the principles, that articulate primordially the space of the concept. Concepts in scientific language as well as in ordinary language can never actually be derived from perception or from images, because the discontinuity of the levels of discourse is founded, at least virtually, by the very structure of the conceptual space in which meanings are inscribed when they draw away from the metaphorical process, which can be said to generate all semantic fields. It is in this sense that the speculative is the condition of the possibility of the conceptual. It expresses the systematic character of the conceptual in a second-order discourse.

P. RICOEUR, THE RULE OF METAPHOR 300 (1977).

In contrast to the theorist's confidence in the stability of meaning, from the rhetorical affirmer's perspective what the critical theorist must come to accept is that there are no "objective" or hard and fast rational truths, and that it is an "illusion that words possess a proper, i.e., primitive, natural, original (etumon) meaning in themselves." Id. at 290 . From the critical theorist's viewpoint, however, the intolerable polysemy (i.e, the multiplicity of meanings) of rhetorical (or figurative) utterance remains an obstacle to clear and consistent meanings - an obstacle that blocks predictability and the standardization of interpretive judgment. In other words, according to the critical theorist, absent clear and comprehensive normative concepts as a basis for judging and appraising interpretive practices, rhetorical speech opens itself to the constant risk of communicative distortion and instrumental manipulation. In this article I maintain that these are dangers which must be taken seriously.

According to the "dialectical" view that this article endorses, the rhetorical affirmer stands in need of the critical theorist's ability to pin down and consolidate the staggering fecundity, and the resulting multiplicity of meanings, that rhetoric's metaphoric discourse tends to produce. Concept formation, and in particular the projection of regulative ideas or heuristic (normative) models, serves this limiting function. On the other hand, the critical theorist stands in need of the rhetorical affirmer's vitalizing images as a check against the deadening effect of prolonged abstraction and conceptual systemization. Figurative utterance, such as metaphor, breaks habituated patterns of meaning by transposing ordinary meaning to a new field. See P. RIcoEUR, supra; J. DeRrida, MARGins of Philosophy 209-71 (A. Bass trans. 1982). In this way, it also helps to keep language in touch with contemporary experience. 
In order to advance this view, it is necessary to identify a critical method, together with appropriate evaluative standards, that will counterbalance the limitations inherent in the rhetorical approach. Put simply, the goal here is to try to see rhetoric as a form of discourse that can stem the dangers of prolonged abstraction and systematic conceptualization while also allowing the critical theoretical tradition to thrive in its own right.

In Part I of this article, I describe in greater detail the tensions touched upon above that divide the current legal culture between rhetorical affirmers on the one side and critical deconners on the other. In Part II, I examine more closely the persuasive discourse that White calls "constitutive rhetoric." White's understanding of rhetoric offers a paradigm for the rhetorical affirmer's viewpoint. In Part III, I begin to explore the limitations and dangers inherent in White's and, by extension, in the rhetorical affirmer's approach. Since Sophocles' Philoctetes provides a working framework for White's most recent collection of essays, I shall focus my critical analysis here. We shall see that a deconstructive reading of White's interpretation of Sophocles' drama reveals hidden motives or beliefs which color the textual meanings that White claims to have uncovered within Sophocles' text. This possibility of distortive reading is a key deconstructivist insight - an insight which rhetoricians can ill afford to ignore.

In Part IV, I attempt to provide a way of bringing together important critical and rhetorical insights. My goal here is to strengthen White's rhetorical perspective by directly confronting the dangers to which the critical deconners seek to alert us. I contend that disempowerment by means of interpretive manipulation, discursive mystification, or subjective instrumentalism - (among the other "cons" of rhetorical enchantment) - must be reflectively anticipated and effectively met in judicial discourse. The illustrative discourse that I offer in this part represents a preliminary effort to embody in concrete form the curative discourse of critical rhetorical practice. This discourse proceeds, first, by explicitly recognizing discrete forms of legal discourse $^{21}$ - whether it is the lay person's ordinary common sense, the philosopher's critical theory, or the jurist's textual interpretation. Second, it seeks to provide a critical method for developing a proper set of checks and balances among these diverse discursive forms. I conclude that interpretive principle, tempered by the disenchanting influence of critical reflection, can provide judicial decisionmakers with the means

21. I.e., distinct ways of thinking and talking and the rhetorical communities that such discursive practices make up. 
to articulate persuasive reasons for achieving legitimate decisional outcomes. More, however, is required: On this view, judicial persuasion must also explain and justify the discourse or discourses which a particular decisionmaker chooses (and by choosing, authorizes) to resolve a given legal dispute. I believe that this step strengthens White's own call for diversity and equality by safeguarding the discrete dialects which make up the shared language of our democracy.

\section{Rhetorical Affirmation Versus Critical DeCONSTRUCTION: MAINTAINING TRADITIONAL BELIEFS IN THE FACE OF "EMANCIPATORY" DISENCHANTMENT}

We crave enchantment. With enchantment come belief and meaning. Deprived of the strength and coherence that our beliefs provide, action becomes problematic. Without coherent standards for thought and judgment and a method for applying them, our acts and judgments threaten to decay into empty gestures, rituals devoid of meaning or purpose, or con games whose sole purpose is to gain power over others. But if there is good reason to cherish belief, there is also reason for caution. Beliefs have their dangers - such as the danger of being "taken in" by the other, being tricked into becoming an unwitting agent of the other's self-serving designs or purposes.

Here, then, is the existential predicament laid bare. We stand caught between two opposing forces: the desire for belief, and the fear of deception. If the former makes thought and action possible, the latter tends to suspend them both in the grip of suspicion. In the legal culture today, the force of belief is manifest in the interpreter's struggle to wrest meaning from textuality (or discourse). The contrary force, that of suspicion, is the critical deconstructivist's effort to disenchant - an effort that claims to liberate the victims of illusory belief from the frozen grip of outmoded or distorted linguistic usages.

Judging by the scholarly literature, the current legal culture seems unable to extricate itself from this existential dilemma. ${ }^{22}$ At the same

22. See, e.g., Levinson, Law as Literature, 60 TEXAS L. REv. 373, 402-03 (1982) ("We can hope that some future conjunction of author and reader will provide a common language of constitutional discourse fit for 'a nation of supple and athletic minds,' but for now we can only await its coming and make do with the fractured and fragmented discourse available to us."); Teachout, Chicago Exposition: The New American Jurisprudential Writing as a Cultural Literature, 39 MERCER L. REV. 767, 848 (1988) ("He had hoped to find something in all that he had read that would make him a better person, more decent and thoughtful, but all he had found was this grand system and that grand system - one grand system after another. And he still seemed no closer than he had ever been to answering the questions that had sent him on his journey in the first place: What did it all mean? Where was it all leading? He was utterly confused, and did not know where to turn."). 
time, one must concede that a productive response to this dilemma cannot lie at either extreme of the spectrum. As already noted, one cannot simply affirm belief without the risk of deception; nor can one simply deconstruct meanings without the risk of nihilism and incoherence. If there is value in both perspectives, therefore, a way must be found for belief to enter into relation with suspicion - without their mutual destruction. I propose that it is the rhetorician's affirmation that provides the most prudent and productive point of departure for establishing such a relationship. Ironically, insights from recent deconstructivist literature help to support this contention. Indeed, the irony of finding help from so unlikely an ally is compounded by the further realization that both critical deconners and rhetorical affirmers face similar limitations. Each group betrays an underlying utopianism. Admittedly, the utopianism of the one may be diametrically opposed to the other; yet, upon closer analysis we find that each provides a necessary check upon the other's omissions and distortions. A brief glance at the major tenets of these opposing perspectives will make this claim clearer.

According to the deconners, rational contradictions and disguised power-plays abound both in legal doctrine and in current interpretive practice. Such a situation, they seem to be saying, is intolerable. Contradiction despoils the law and those legal institutions by which the law is implemented. For its part, the hidden power-play only masks the political disempowerment that interpretive practice produces. The implicit conclusion is that the taints must be removed. Unfortunately, what the deconners have in mind as a replacement is not always so clear. ${ }^{23}$ Another curiosity insufficiently discussed in the critical literature is the deconners' reticence regarding the model of rationality that informs their critique. The question here is, what is it that renders rational contradiction so reprehensible? ${ }^{24}$ Is it the liberals' failure to

23. And when they do emerge, the deconners' goals may strike some as jejune. See, e.g., Singer, The Player and the Cards: Nihilism and Legal Theory, 94 YALE L.J. 1, 67-69 (1984) (describing the "general goals" of a "social vision" as the prevention of cruelty, the alleviation of misery, and the alteration of social conditions that cause loneliness). According to Singer: "The goal of politics and law should be to organize social life in a way that will maximize the number and variety of social situations in which contact among people is experienced as mutually selfvalidating and loving rather than mutually isolating and threatening." Id. at 70 . Needless to say, such laudable goals as these will require more specificity with regard to the method of their implementation than Singer provides.

Other writers within the Critical Legal Studies movement, however, have faced more directly the challenge of presenting a specific positive program. See, e.g., Kelman, Trashing, 36 STAN. L. REV. 293, 297-304 (1984) (noting a broad range of CLS proposals, including advocacy in behalf of housing code enforcement, affirmative action, clinical legal education, state reform of work rules and child-care programs, along with a variety of other substantive and theoretical claims).

24. See, e.g., Stick, Can Nihilism Be Pragmatic?, 100 HARv. L. REv, 332, 346 (1986) (describing a CLS tendency to presuppose that "legal reasoning, to be rational, must operate by 
perfect their system that is so mortifying to the deconners? ${ }^{25}$ Do the deconners have in mind some other mode of thinking, or some other political system, within which logical contradiction may lose its sting? Or, if irrationality cannot be avoided, have they in mind a political alternative that will more effectively ensure that human violence will be?26 The answer remains unclear. In any event, whether the decon-

means of deductive proof and agreed-upon first principles, which function like the axioms of Euclidean geometry"). According to Stick, this constricted vision of rationality "distorts both contemporary liberal legal theory and current legal practice." Id. Cf. Unger, The Critical Legal Studies Movement, 96 HARV. L. REv. 563, 572-73 (1983) (denouncing current legal theory and practice as "an endless series of ad hoc adjustments" and as suffering from a "looseness" of theoretical support - a situation that has been compensated for by "rhetorical posturing," and that "ends up as a collection of make-shift apologies").

For a more supportive description of this same "ad hoc" process, see K. LLEWELLYN, THE COMMON LAW TRADITION 178 (1960) ("I submit that the signs to be looked for, though wholly unstandardized, are nonetheless as gross and unmistakable as road signs, and that there are obvious and valuable procedures of interpretation and use which are well-nigh as simple and communicable as the driving of a nail."); see also Kronman, Alexander Bickel's Philosophy of Prudence, 94 YALE L.J. 1567, 1570 (1985) ("Abstract theories and moral imperatives, [Bickel] maintained, have a 'tyrannical tendency'.... What we require, if we are to remain both a good society and a viable one, are the arts of compromise,' the 'ways of muddling through' that permit us to reach an accommodation between our principles and the complex, murky, and often resistant reality on which these principles operate.").

The fallacy of the opposition expressed above, between hermeneutics or rhetorical practice on the one hand and critical theory on the other, has been captured well by Ricoeur:

Freedom only posits itself by transvaluating what has already been evaluated. The ethical life is a perpetual transaction between the project of freedom and its ethical situation outlined by the given world of institutions. . . However, on its side, a hermeneutic which would cut itself off from the regulative idea of emancipation would be no more than a hermeneutic of traditions and in these terms a form of philosophical restoration[;] . . . the relation between a project of freedom and the memory of its past conquests constitutes a vicious circle only for analytic understanding, not for practical reason.

Ricoeur, Ethics and Culture: Habermas and Gadamer in Dialogue, 17 PHIL. Today 153, 165 (1973).

25. See, e.g., R. Unger, 1 Politics: FAlse Necessity 455 (1987) ("To make society resemble what liberal politics to a considerable extent are already like, we would have to change the institutional form of the state and of the conflict over governmental power and push the liberal vision beyond the point to which its creators have up to now been willing to take it."); see also Unger, The Critical Legal Studies Movement, supra note 24:

[T] he practice of expanded doctrine begins all over again the fight over the terms of social life. It is the legal-theoretical concomitant to a social theory that sees transformative possibilities built into the very mechanisms of social stabilization and that refuses to explain the established forms of society, or the sequence of these forms in history, as primarily reflecting practical or psychological imperatives .... One way to clarify the origin and character if not the justification of the ideal that inspires our programmatic institutional ideas is to say that our program arises from the generalization of aims more or less shared by the great secular doctrines of emancipation of the recent past - liberalism, socialism, and communism — and by the social theories that supported them.

Id. at 583-84 (emphasis added). See also Stick, supra note 24, at 342, 360, 383 (noting that nihilistic CLSers, such as Joseph Singer, betray a positivistic craving for certainty that leads them to impose external standards of rationality on practical discourse). In Stick's view, theories of this type represent the romantic Cartesian who has "lost all hope."

26. See R. UNGER, KNowledge AND Politics, supra note 1, at 3 ("[T] he house of reason in which $I$ was working proved to be a prison-house of paradox whose rooms did not connect and whose passageways led nowhere.").

The dangers associated with supplanting more familiar ("classical") modes of reasoning with a power- or passion-driven modality have been pointed out by Patrick Corbett in his superlative 
ners' ideal is one of perfectible ("contradiction-free") reason or perfectible ("actualized") human nature, ${ }^{27}$ the following impression remains: the deconners seem to be driven by ideals which, to the extent that they are articulated, appear as vulnerable to the CLS critique as those liberal ideals they condemn. Yet, notwithstanding the evidence they've uncovered of rampant contradiction and mystification within the legal culture, the deconners' vision remains undaunted. Theirs is the defiant hope that history's constraints are shackles that future reform can confidently shatter.

work, Ideologies, which notes, for example, Hitler's blunt admission that the Jew of Nazi mythology had to be invented so that Hitler and the Germans would have something to hate, and that the only thing the movement stood for was the power of its leader. P. CORBETT, IDEOLOGIES 153 (1965).

The dangerous naivete of Unger's approach to an "omni-transformable" human nature is well captured by Bernard Yack in Roberto Unger, A Work in Constructive Social Theory (Book Review) 10 HARV. L. REV. 1961, 1976 (1988) ("Unger, unlike Nietzsche, avoids the unpleasant implications of his ideas. He pushes his ideal, the celebration of our 'context-smashing abilities' to its logical conclusion. We must act like proud and haughty masters to live up to his ideal. Of course, he adds, his citizens will join a loving and gentle character to their other, more warlike virtues.... Yet he gives little indication how they can behave like both proud masters and gentle souls.").

27. The "visionary insight" that seems to drive Unger's work calls for the establishment of social and psychological conditions that will allow everyone to achieve their fullest creative potential. See, e.g., Unger, The Critical Legal Studies Movement, supra note 24, at 584 (supporting the idea that weakening social divisions and hierarchies "would reveal deeper individual and collective identities and liberate productive and creative powers"); see also R. UNGER, PASSION 219 (1984) ("Love alone can correct this failure of the ability to imagine diversity and community."); R. UNGER, FALSE NECESSITY, supra note 25, at 1, 279-80 (reasserting the need to break with "the tedious, degrading rhythm of history" and with "narcoleptic routines" in order to "gain practical, emotional, and cognitive access to one another"). The motivating force of Unger's vision in False Necessity is "reconstructive freedom" or "negative capability" - a force by which formative institutional and imaginative structures may be altered. The gain to be derived from such emancipatory empowerment (a process Unger also refers to as "trashing the script," id. at 319) is expressed in False Necessity as follows: "Disentrenchment of formative contexts provides societies with a range of material and intangible advantages, all the way from the encouragement of the development of productive capabilities to the exercise of a more conscious mastery over social circumstance." Id. at 279. Unger notes that "disentrenchment" may be achieved either through "consensual, decentralized, and participatory methods or through centralized command and coercion." Id. at 286. The latter route, "mobilizational despotism" (as illustrated by modern centrally planned economies), according to Unger, "should not be mistaken for an entrenched order of division and hierarchy." Id.

Of course, not all supporters of Critical Legal Studies are necessarily driven by some overarching, coherent vision. Mark, for instance, Duncan Kennedy's words:

[W] hat we ought to do is not worry, first, about getting things clear within a single, coherent analytic vocabulary constructed synthetically or just borrowed from one of the traditions.... It's not to grasp or control [people's] minds by the explicitness and the beauty with which we get at the real structure of reality. But rather to operate in the interspace of artifacts, gestures, speeches and rhetoric, histrionics, drama, all very paradoxical, soap opera, pop culture, all that kind of stuff.

Gabel \& Kennedy, Roll over Beethoven, 36 STAN. L. REV. 1, 9 (1984). The driving force behind this (nonlinear) perspective might be described as a yearning for some engulfing incoherence. See, e.g., id. at 23 ("I want paradox and unconsciousness. Paradox and unconsciousness allow one experientially, existentially, to exist outside of the contradiction-space of separateness and unity."). One of the labels Kennedy offers for this experience is "interstitial" freedom. Id. at 5354. 
For their part, the rhetorical affirmers appear less willing to endorse the type of critical reasoning upon which such counter-historical ideals depend. ${ }^{28}$ In fact, the rhetorical affirmers seem to be saying that the deconners have got reason wrong. ${ }^{29}$ And indeed, it is possible to argue that despite their protestations to the contrary, the deconners remain caught up in the quest for certainty and rational order that began in the Age of Enlightenment; ${ }^{30}$ that they may in fact be trying to establish a kind of philosophical "City of God" on earth. ${ }^{31}$ Yet, if the deconners' utopian state lies somewhere just over the horizon, the rhetorical affirmers' hopes are just as utopian, although derived from a different source. It may be suggested that the rhetorical affirmers'

28. Kant's model of critical reason as a source of ahistorical, universalistic norms informs some of the critical theorists' writings. For example, Habermas' social theory and Piaget's and Kohlberg's cognitive psychology (upon which Habermas has relied) reveal a strong affinity with Kant's (rationalistic/context-free) epistemology. See J. HABERMAS, CoMmUNICATION AND THE Evolution of Society 69-94 (T. McCarthy trans. 1979); L. KoHLbERG, THE Philosophy of Moral Development 192-226 (1981); J. Piaget, Psychology AND Epistemology 63-88 (1978).

29. See Kronman, supra note 24; see also E. Grassi, Rhetoric As Philosophy 20, 34 (1980) ("'[R]hetoric' is not, nor can it be the art, the technique of an exterior persuasion; -it is rather the speech which is the basis of the rational thought. ... The metaphor lies at the root of our knowledge in which rhetoric and philosophy attain their original unity."); Fish, Dennis Martinez and the Uses of Theory, 96 YALE L.J. 1773, 1785 (1987) ("Judging, in short, cannot be understood as an activity in the course of which practitioners regularly repair for guidance to an underlying set of rules and principles.").

30. In other words, by continuing the opposition between tradition and criticism, emancipatory deconners remain entrenched within the same debate that thinkers spawned in the period of the Enlightenment. See R. Bernstein, Beyond ObJectivism AND Relativism 37 (1983). In this respect, therefore, the deconners' critique remains parasitic upon mainstream thought. See R. RoRTy, Philosophy AND the Mirror of NATURE 368-70 (1983) (distinguishing "mainstream," "systematic" philosophy, in the tradition of Descartes, Locke, and Kant, from "peripheral," "edifying" philosophy, exemplified in the writings of such figures as Goethe, Kierkegaard, William James, Dewey, the later Wittgenstein and the later Heidegger). According to Rorty, systematic philosophers typically say things like this: "Now that such-andsuch a line of inquiry has had such stunning success, let us reshape all inquiry, and all of culture on its model, thereby permitting objectivity and rationality to prevail. . ." The unsystematic, marginal thinker, in contrast, typically is reactive. Such philosophers "offer satires, parodies, aphorisms. They know their work loses its point when the period they were reacting against is over. They are intentionally peripheral." Id.

31. For example, although Unger draws lines sharply demarcating religion and politics from philosophy, he appears to belie this tripartite division by virtue of the vision that drives his work. See R. Unger, KNowledge AND Politics, supra note 1. See also Kronman, Book Review, 61 MINN. L. REV. 167, 203 (1976) (Unger acknowledges in a letter to Kronman, reprinted in an appendix to the review, that Knowledge and Politics "is a Christian book because it affirms that mankind can progress toward the ideal (beatitude) in history but that they cannot achieve it in history.").

For a wry correlation between Augustinian Christianity and secular political utopianism, see Bertrand Russell's History OF WeSTERN Philosophy 364 (1945) (equating "Yahweh" with "Dialectical Materialism," "The Messiah" with "Marx," "The Elect" with "The Proletariat," "The Church" with "The Revolution," "Hell" with "Punishment of the Capitalists," and "The Millennium" with "The Communist Commonwealth"). 
dominant vision is flavored with a kind of nostalgia ${ }^{32}$ for a time when the power of the word seemed to shine forth with greater radiance than it does today; for a time when high culture seemed to blossom for everyone (or at least the citizenry, if not their servant class); for a time when great stories (of gods or heroes) were broadly shared as part of the politics as well as the popular and artistic culture of the day; for a time, in short, when cultural narratives were rich and vibrant. ${ }^{33}$ On this view, if the utopian vision of the deconners is yet to be, that of the rhetorical affirmers may be traceable to a time that may never have been. Indeed, there is a notable tendency among the rhetoricians to turn toward classic texts of human history - or even prior, as when the text in question speaks of divine creation. ${ }^{34}$ Simply put, the affirmer's vision may be said to belie a tendency to glorify the "transcendent" phenomenon of meaning itself. ${ }^{35}$ Indeed, there is reason to wonder whether the rhetorical affirmers surrender to an inchoate drive

32. Cf. Posner, The Jurisprudence of Skepticism, 86 MiCH. L. REv. 827,830 (1988) (describing Dworkin's "right answer" thesis as reflecting a "nostalgia for lost certitudes").

33. See, e.g., ARISTOTLE, supra note 3. Evidencing the power of the ancient Greek poets as a common source of moral or ethical truth, and their presumed familiarity to the intelligent reader, Aristotle typically supports his claims by prefacing them with such phrases as this: "It is this that Sophocles's Antigone clearly means. ..." id. at 78; or, "We can well believe the poet [Homer] when he says. . .," id. at 69 ; or, "[T] herefore, the poet [Euripides] says. .. ," id. at 71 . See also Joseph Story's eulogy to classical learning:

What has been already said rather presupposes than insists upon the importance of a full possession of the general literature of ancient and modern times. It is this classical learning alone, which can impart a solid and lasting polish to the mind, and give to diction that subtile elegance and grace which color the thoughts with almost transparent hues. It should be studied, not merely in its grave disquisitions, but in its glorious fictions, and in those graphical displays of the human heart, in the midst of which we wander as in the presence of familiar but disembodied spirits.

It is by such studies, and such accomplishments, that the means are to be prepared for excellence in the highest order of the profession. The student, whose ambition has measured them, if he can but add to them the power of eloquence, (that gift, which owes so much to nature, and so much to art,) may indeed aspire to be a perfect lawyer.

Story, The Value and Importance of Legal Studies, in R. FERGUSON, LAw AND LETTERS IN AMERICAN CULTURE (epigraph) (1984).

34. See, e.g., Cover, The Folktales of Justice: Tales of Jurisdiction, 14 CAP. U. L. REv. 179, 182 (1985) ("[T] he claim to a 'law' is a claim as well to an understanding of a literature and a tradition. It doesn't matter how large the literature or how old the tradition. Sinai might have been yesterday or four thousand years ago; the text might be two tablets or the infinity of Borges' library of Babel."). See also Perry, The Authority of Text, Tradition, and Reason: A Theory of Constitutional "Interpretation," 58 S. CAL. L. REv. 551, 561 (1985) ("Some commentators have recently explored the similarities between legal interpretation and literary interpretation. But the sacred-text analogy is better than the literary-text one. The relationship between a political community (and tradition) and its foundational text is much more like the relationship between a religious community (and tradition) and its sacred text than the relationship between an interpretive community' (to use Stanley Fish's term) and whatever literary texts happen to engage it." (citations omitted)).

35. See, e.g., H. GADAMER, TRUTH AND METHOD, supra note 13, at 419 (1975) (building upon Heidegger's phenomenology of Being, which describes the structure of human understanding as ec-static (or standing out from itself). According to Gadamer: "It is not being-in-itself that is increasingly revealed when Homer's Iliad or Alexander's Indian Campaign [for example] speaks to us in the new appropriation of tradition but, as in genuine conversation, something 
to recapture - and project creatively ${ }^{36}$ - from the texts we have inherited some promise of meaning, some transcendent covenant. ${ }^{37}$ Perhaps it is this yearning that underlies the rhetoricians' aspiration to perfect interpretive skills rather than to cultivate deconstructive critique.

Thus if the deconners' utopian desire, reflected in their insistence upon possibilities-yet-untold, seems naive in its implicit repudiation of history's lessons, a similar naiveté manifests itself in the rhetorical affirmers' faith in our ability to interpret confidently and assess critically. in our own time the seminal or power-laden texts ${ }^{38}$ that we inherit from the past. The question confronting the rhetorical affirmers is this: By what contemporary standards are the interpreter's interpretations to be justified and appraised? Or, putting the matter differently, by what authority do we warrant what is valid among the possible interpretive meanings of the traditional texts that we inherit? Implicit here as well is the additional question, what form of discourse shall we deem authoritative? ${ }^{39}$

emerges that is contained in neither of the partners by himself." And: "Someone who understands is always already drawn into an event through which meaning asserts itself."- Id. at 446.

Nevertheless, the rhetorical affirmers' search for meaning remains context-bound - even if the context must be created, at least in part, by entering into the play of meanings that inherited texts, including ancient tales or biblical narratives, supply. The deconner, on the other hand, truer perhaps to the project of the Enlightenment, appears to pursue norms that are context-free: divorced both from inherited texts and from any other constraining influences.

36. Or, put in more explicitly eschatological terms, to redeem, or complete possible meanings. See, e.g., Garet, Meaning and Ending, 96 YALE L.J. 1801, 1811 (1987) (describing Cover's belief that "efforts to realize the future ideal world through heroic legal action - or "lawful Messianism' - do not necessarily 'tend to undermine the normal tension between present and future' ") (emphasis in original) (quoting Cover, Bringing the Messiah Through Law: A Case Study, in Nomos XXX: Religion, MORALITY AND THE LAw (forthcoming 1988)).

37. See Garet, supra note 36, at 1811-13. Expanding upon Cover's image of "law as a bridge" in order to include biblical law (i.e., "the rainbow "arc of the covenant" ") - the prototype of the covenant that God entered into with the people. Garet writes that the figure of the "rainbow arc" serves as

a message to wanderers that there will come a terminus to their wanderings, and that what looks from one vantage point like destruction looks from a different perspective like a promise of peace and reunion. Thus the rainbow marries the contraries of life and death, this world and the other world, the shore of embarcation and the shore at which the navigator lands ....

Id. at 1813 .

38. What Cover calls the "sacred narratives" or "folktales of justice." See Cover, supra note 34 , at 182 .

39. For example, should we resort to the "naive" authority of the figurative utterances of ordinary speech? See, e.g., Sherwin, supra note 4, at 737-39 (1988) (discussing the role of ordinary common sense as one among other discrete forms of discourse in the criminal process). Consider also such authoritative metaphoric usages as the "wall of separation" (between church and state) or the "fruit of the poisonous tree" (as a basis for excluding evidence at a criminal trial) or the existence of "penumbras" (as a basis for extending constitutional rights, such as the right to privacy). Theory, too, has its share of ruling metaphors. See, for example, the continued authority of the image of the "marketplace" and the "invisible hand" in legal theory (discussed in B. ACKERMAN, RECONSTRUCTING AMERICAN LAw 94-101 (1984)) or the image of due pro- 
One of the dangers that the rhetorical affirmers risk by failing directly to address questions regarding normative standards is to lose sight of, or grossly underplay, the manifold ways in which meanings are either lost or distorted over time - and often for less than benevolent reasons. ${ }^{40}$ Pertinent in this regard are such familiar historical examples of communicative distortion as ideological or instrumental manipulation, ${ }^{41}$ false consciousness, ${ }^{42}$ and the domination of others..$^{43}$ These concerns are especially germane to the legal culture where

cess as a "factory that has to devote a substantial part of its input to quality control" (discussed in H. Packer, The Limits of THe Criminal SANction 165 (1968)).

Or do we find the warrant we seek in the authority of rational systems of regulative concepts or "rational" principles (such as Rawls' constructivist principles, or Dworkin's system of comprehensive rights); or in abstract empirical models, such as the utilitarian's model of the individual as a perennial calculator of particular utility pay-offs, such as happiness, wealth, or love. (For a discussion of love as a utility, see Griffiths, Ideology in Criminal Procedure, 79 YALE L.J. 359,377 (1970).) Or perhaps "self-actualization" provides the guiding norm for our interpretive judgments. See Baker, Realizing Self-Realization, 130 U. PA. L. REV. 646 (1982).

It is by checking and balancing the semantic ambiguity of rhetorical utterance with disparate - or even incommensurate and incompatible - normative models or ideals that the normatizing function of speculative discourse emerges as a virtue within interpretive practice. Checked and balanced, in turn, by rhetoric's sensitivity to context, and to the particular needs and desires of the parties or persons who will, or may potentially, be affected by a given judgment, critical theory may be seen to operate within the domain of rhetoric itself. In this domain, recourse to "self-evident" truths or norms is no longer possible. Persuasion, based upon good reasons, and the controversy that this type of practical discourse naturally generates, cannot be avoided.

40. In Heracles' Bow, for example, White displays a rather dismissive view toward the human tendency to disturb communicative clarity intentionally for the sake of gaining personal power over another. Compare J.B. WHITE, HERACLES' Bow, supra note 5, at xv (noting that while law "is explicitly about the use of official power" this is something that does not warrant "much remark at the outset"), with Cover, supra note 4, at $1601 \mathrm{n} .2$ ("The violent side of the law and its connection to interpretation and rhetoric is systematically ignored or underplayed in the work of both Dworkin and White."). See also Minow, supra note 4, at 1865 n.20 ("My concern about White's work is that it paints too cozy a picture of the world, assuming agreement and commonality precisely where they are lacking."). But see J.B. WHITE, WHEN WORDS LOSE THEIR MEANING, supra note 5, at 114-37.

41. See, e.g., P. CORBETT, IDEOLOGIES, supra note 26. Corbett describes ideology as follows: [Ideology is] any intellectual structure consisting of: a set of beliefs about the conduct of life and the organisation of society; a set of beliefs about man's nature and the world in which he lives; a claim that the two sets are interdependent; and a demand that those beliefs should be professed, and that claim conceded, by anyone who is to be considered a full member of a certain social group.

Id. at 12. See also Sherwin, supra note 4 (noting the consequences of covert judicial application of ideological and instrumental presuppositions).

42. See J. HABERMAS, supra note 19, at xix ("The mode of production of material life conditions the general process of social, political, and intellectual life. It is not the consciousness of men that determines their existence, but their social existence that determines their consciousness.") (quoting K. MARX, A CONTRIBUTION to THE CRITIQUe OF POLITICAL ECONOMY 20-21 (Dobb ed. 1970)).

43. Either by brute force or by imposing subjective, self-beneficial policy preferences. See T. HoBbES, LEviathaN 17 (Herbert Schneider ed. 1958) ("[I]t is men and arms, not words and promises, that make the force and power of the laws."). See also Sherwin, Opening Hart's Concept of Law, 20 VAL. U.L. REV. 385, 406 n.83 (1986) (distinguishing public acquiescence to power from public acceptance of legitimate authority). 
power and violence go hand in hand with discourse itself. 44 Thus, when it comes to dealing self-reflectively with the dangers of inequality, disempowerment and domination, recourse to the art of rhetoric alone will not suffice. And it is precisely this danger about which the deconners have been warning us.

The deconners have a point. Regrettably, however, too often it appears to serve not only as their point of departure - i.e., as a springboard to the critique of inherited legal texts and of traditional interpretive practice - but also as their point of destination. One may concede that as a means of exposing and perhaps "cleansing" the culture of outmoded or disfavored beliefs, the method of critical disenchantment has an important role to play within legal debate. Those who would subject inherited values to suspicion, however, must also be willing to do the same with their own normative impulses. And if, upon critical reflection, it turns out that suspicion for its own sake impels the critic's judgment, that judgment must become irretrievably suspect. Indeed, Unger's recent work clearly shows that this is the case. By advocating the continual subversion of inherited concepts, beliefs, and social institutions, Unger takes the goal of trashing for trashing's sake to its logical extreme. ${ }^{45}$ In the process, he reveals the utter instability and incoherence of such a way of life. ${ }^{46}$ As Yack vividly puts it: "Imagine a world in which every individual challenges every social structure with the haughtiness of a master, the fanaticism of a prophet, and the intelligibility of an aphasiac. That is Unger's image of the good life."47

If Unger's "utopian" vision seems undesirable, its avoidance hinges upon not taking deconstructive critique to its logical extreme. An alternative approach, the one I am arguing for here, would take the rhetorician's affirmation of meaning within interpretive practice as the point of departure for the judicial decisionmaking process. Critical reflection must, however, give pause along the way. With the intervention of suspicion, the forewarned decisionmaker learns to anticipate the delegitimating dangers of her own (or others') textual or

44. See B. ACKERMAN, supra note 17, at 3 (discussing the ways in which lawyers translate their clients' grievances into a particular "language of power"); Cover, supra note 4.

45. See, e.g., R. UNGER, supra note 25, at 319-24 (describing the need to "trash the script" provided by inherited contexts so as to "move toward higher levels of negative capability" and increase "the effectiveness of structure-breaking action").

46. See Yack, supra note 26, at 1967-77 (noting the inescapable contradictions that inhere both in Unger's notions of "structure-denying structures" and his professed goal of realizing humanity - a goal that requires precisely the kind of embodiment that his descriptions of human nature painstakingly deny).

47. Id. at 1975. 
interpretive distortions or manipulations. ${ }^{48}$ Consequently, she may more deliberately (and thus perhaps more effectively) strive to avoid both the appearance and the substance of illegitimate discursive practice - without casting aside her belief in meaning itself. If the rhetorician must learn the lesson of suspicion, however, the deconner must in turn learn to cultivate the rhetorician's art. That is, she must explicitly identify and persuasively affirm preferred normative values or beliefs. In this way, the critical deconner can take greater responsibility for meaning's advent. This interaction between affirmation and suspicion allows meaning and controversy to coexist within the legal culture in particular, and within our liberal, pluralistic society as a whole.

In short, according to the proposed model of critical rhetorical practice, the urge to perfect reason or human nature or meaning itself must be checked by an awareness of our existential predicament. We cannot ignore the violence and distortion, the subjective instrumentalist drift of rhetorical utterance, or the rhetorician's apparent inability to generate a body of consistent norms to regulate interpretive practice. Nor can we allow the desire for meaning to stupefy, through persuasive enchantment, the sobering fear that we have been "taken in" by another. Indeed, the need for suspicion is all too vividly supported by history's lessons in cruelty and injustice. In the face of this insight, the critic's counter-historical utopian vision - like the scientific rationality that once presumed the power to arrange human affairs, ${ }^{49}$ may yield to humbler aspirations. Thus, if rhetoric, with its characteristic emphasis on practical reasoning, may provide a more appropriate point of departure for resolving human conflicts than classical science, ${ }^{50}$ with its systematic search for rational clarity and neatness, ${ }^{51}$ or than critical deconstruction, with its emphasis on dis-

48. See Sherwin, supra note 4; see also Cover, supra note 4, at $1611 \mathrm{n} .24$ ("I fully agree that the dominant form of legal thought ought to be interpretive in the extended sense of the term.").

49. From Bentham to Langdell. See R. MCKeon, RHEToric 9 (1987).

50. That is to say, science in the tradition of classical or Newtonian (as opposed to quantum) mechanics. Unlike classical theory, quantum theory takes into account Heisenberg's "uncertainty principle." According to Heisenberg's principle, subatomic measurements are inescapably indeterminate. See W. HeIsenberg, PhySICS AND BEYOND 81 (1971) (noting Einstein's famous "rebuttal" to quantum uncertainty: namely, that "God does not throw dice"). The more recent science of "chaos" cuts away even further at the tenets of Newton's physics. See J. Gleick, CHAOs 6 (1987) (noting that if quantum theory eliminated the Newtonian dream of a controllable measurement process, "chaos" eliminates the Laplacean fantasy of deterministic predictability).

51. By this I do not mean to disparage the value of regulative concepts or models as heuristic guides for critical interpretive practice. This resource plays an important role in communication. See, e.g., P. BERGER \& T. LUCKMANN, THE SOCIAL CONSTRUCTION OF REALITY 106-07 (1966) ("[T]he symbolic universe is not only legitimated but also modified by the conceptual machineries constructed to ward of the challenge of heretical groups within a society."); G.H. VON WRIGHT, EXPLANATION AND UNDERSTANDING 28 (1971) (expressing the need to under- 
enchantment, rhetorical affirmers must nevertheless take seriously the critical lessons of suspicion.

In what follows, I attempt to reset the context for the debate that currently rages between critical deconners on the one side and liberal defenders on the other. ${ }^{52}$ I contend that to engage in a more fruitful discourse, we must shift away not only from the search for neutral or universal principles as a putatively legitimating basis for the judicial

stand "the concepts and rules which determine the 'social reality' of the agents whom he studies"); H. HART \& T. HoNoRE, CAUSATION AND THE LAW 3 (1985) (describing the utility of isolating the "main features of the concepts latent in causal language ..."). Theory's heuristic models and normative ideals, no less than rhetoric's root metaphors, dramatic characterizations and inventive argumentation, have a part to play in the way legal controversies are resolved. See also W. JAmes, What Pragmatism Means, in The Writings of William James 376, 382 (1967) ("[I]deas . . . become true just in so far as they help us to get into satisfactory relation with other parts of our experience...." (emphasis omitted)).

However, to the extent that regulative concepts or models do guide and inform interpretive practice, they must be regarded as variable and contextual rather than as fixed and essential. See S. Toulmin, Human UNDERSTANDING 21 (1977); J. Habermas, supra note 19, at xvii-xviii (describing the ideal speech situation and the fundamental norms built into it as "a practical hypothesis"). It is this emancipation from a Cartesian, universalistic normative frame of reference that is the hallmark of post-modern concept-formation. But see J. HABERMAS, supra note 19 , at 5 ("I have proposed the name universal pragmatics for the research program aimed at 'reconstructing the universal validity basis of speech.").

The overall effect of rejecting the promulgation by courts of decontextualized norms as a decisional point of departure - whether in the form of natural rights, utility maximization, or unreasoned intuitions of common sense, - is to delimit the legitimate range of judicial decisionmaking. In this respect the view of judicial constraint that this article endorses (see infra Part III) is not inconsistent with John Hart Ely's emphasis upon reinforcing representation and safeguarding participatory democracy in the processes and distribution of government. See J. ELY, supra note 10, at 87, 102-03, 181; see also B. ACKERMAN, supra note 2, at 24-28.

52. For a discussion of the effectiveness of resetting the context of a debate, see Tammelo, The Rule of Law and the Rule of Reason in International Legal Relations, in LA THEORIE DE L'Argumentation: Perspective et APplications 335, 358 (1966) (noting the advantages of transposing the setting of an analytical problem by shifting it to a more appropriate "place" of argument (to a new topos) which introduces different problems that are specific to it). This move is central in traditional rhetorical practice. See R. MCKEON, supra note 49, at 31 ("[O]ne cannot form a sound judgment of a thing without having complete knowledge of it; and topics is the art of finding in anything all that is in it.") (quoting Vico). McKeon comments:

[C]ommonplaces of invention may open up the perception of new meanings and applications even in a familiar text, which in turn uncovers previously unperceived lines of arguments to unnoticed conclusions which were not there until they were made facts by discovery. . . . The uses of the commonplaces of creativity (i.e., categories or topics) erects and fills the commonplace as a storehouse of the familiar to provide materials for commonplaces as instruments for the perception, creation, arrangement, and establishment of the new in existence, experience, discursive exploration, and inclusive organization.",

Id. at 36.

Compare Rawls' recent shift from a "universalizable" rational perspective (in the sense of Kantian epistemology) to a more pragmatic, expressly political perspective. See, e.g., Rawls, The Idea of an Overlapping Consensus, 7 OxFord J. LEGAL STud. 1 (1987). According to the latter viewpoint, history, culture and character presumably cannot be washed away. (I say "presumably" because Rawls' continued reliance upon the analytical device denoted in his work as the "veil of ignorance" leaves unclear the relationship between practical grounds for judgment and recourse to a rational agency which precludes disagreement.) However, to the extent that Rawls has embraced a practical/political type of discourse, the rhetorical perspective assumes a significant role. 
decisionmaking process, ${ }^{53}$ but also from critical deconstruction for its own sake. ${ }^{54}$ Rhetoric provides a constructive alternative to the irreconcilable conflict between the rigid categories of "subjective" and "objective" and the contradictions resulting from their application. Rhetoric opens up a space for interpretive synthesis and moderation. By adopting such an approach, Cartesian epistemology gives way to a view according to which meanings emerge from individual acts of contextualized interpretation. According to this view, "prejudice" and "uncertainty" come to be seen not as obstacles to rational debate, but rather as inescapable facts of life. There is no escape, this view tells us, from the strain of irresolution that accompanies normative discourse. Moreover, in contrast to the totalizing critique of CLS, the rhetorical approach opens up a space for interpretive synthesis and moderation among competing claims and interests. ${ }^{55}$

By deliberately embracing the controversy that attends collective normative discourse, critical interpretive practice ${ }^{56}$ provides a means of maintaining (or building anew) the "overlapping consensus" 57 that both founds and legitimizes our liberal democracy. At the very least, it offers a constructive alternative to the rancorous and unproductive debate in which critical theory is endlessly pitted against the interpretive tradition. ${ }^{58}$ Thus, if Cover is right to warn us of the violence of the word - and I believe that he is - still this must not unduly diminish our appreciation of its power to resolve conflict, to heal pain

53. This is not to say that foundational principles may not be broadly shared, but only that they cannot escape the controversy of debate that attends all normative (non-neutral) commitments. But see Wechsler, supra note 2; Greenawalt, The Enduring Significance of Neutral Principles, 78 COLUM. L. REV. 982 (1978).

54. Cf. R. UNGER, supra note 25 , at 484 ("The point of plasticity, broadly speaking, is to increase the opportunity for experiment and innovation in social life.").

55. See B. Ackerman, supra note 2, at 359 ("The task of political conversation is to make it possible for each citizen to defend his power without declaring himself intrinsically superior to any other citizen. ... Rather than using political power to subordinate people to the pursuit of a single common good, rather than using philosophical argument to convert people to a single common understanding, liberal theory invites people to pierce their substantive disagreements and achieve a deeper unity - in the fact that they are all seeking to define themselves through a common process of dialogue."). See also Cornell, The Institutionalization of Meaning, Recollective Imagination and the Potential for Transforming Legal Interpretation, 136 U. PA. L. REV. 1135, 1217 (1980) (noting that Ackerman's notion of dialogue as a normative relationship expands the Hegelian understanding of reciprocal symmetry to include a substantive understanding of inequality).

56. See infra Part IV.

57. See Rawls, supra note 52.

58. This dichotomy has a long history. It dates back to ancient disputes over the nature of scientific knowledge or "truth" (episteme) and practical reason or "belief" (doxa). See, e.g., R. BERNSTEIN, supra note 30, at 112; H. GADAMER, REASON IN THE AGE OF SCIENCE 1-20 (1983); E. GRASSI, supra note 29, at 18-34; G.H. VON WRIGHT, EXPLANATION AND UNDERSTANDING 1-33 (1971). 
and anguish, to provide meaning when meanings fail, and to inspire belief to counter the skeptic's charge. Conversely, however, to the extent that all forms of power corrupt - the power of the persuasive image no less than that of the regulative concept ${ }^{59}$ - upon entering the realm of rhetoric, suspicion must remain the touchstone for prudent judgment and wisdom in action.

Before we can begin to build a bridge that will bring belief into relation with suspicion, the ground for its key supports must be carefully examined. Our first task, in Part II, will be to take a closer look at the realm of rhetoric and the text-based meanings that it professes to affirm. The pathbreaking work of James Boyd White will provide a suitable point of departure.

\section{Constitutive Rhetoric: Recognizing the Possibilities of Self, Community, and Culture in Persuasive DISCOURSE}

In his most recent book, Heracles' Bow, ${ }^{60}$ James Boyd White explores the meaning of persuasive discourse, how it determines who we are, the community we share with others, and the culture to which we belong. For lawyers, White says, the art of rhetoric represents a way of life. ${ }^{61}$ This is not the debased and debasing life of the sophist, that word merchant for whom rhetoric means persuasion for its own sake alone. Indeed, rhetoric of this kind serves as White's central target throughout the book. In contrast to the sophist's chameleon-like character and instrumentalist craft - catering to the demands of the moment - White portrays an altogether different type of character and discourse. He speaks of the other in terms of friendship, not combat. In place of cunning or deceitful manipulation White extols sincere and open persuasion, the type of persuasion that takes place among equals in discourse. 62

White calls this type of persuasive discourse "constitutive rhetoric." His claim is that self, community, and culture are constituted and characterized by the way we choose to speak to one another (as judges, lawyers, scholars, or lay folk). Whether wittingly or not, we decide in our conversations with each other who we are - both indi-

59. On the subject of regulative ethical principles, see J. HABERMAS, supra note 28 , at 78-90 (discussing psychologist Lawrence Kohlberg's stages of moral consciousness which culminate in the individual's definition of right in relation to self-chosen ethical principles which appeal to logical comprehensiveness, universality, and consistency).

60. See supra note 5.

61. Id. at xii and 238.

62. Id. at 128-29. 
vidually and collectively. For it is through discourse itself that who we are and the community and culture we belong to take on an embodied existence in the world. ${ }^{63}$ In White's view, therefore, choosing one type of discourse over another is an activity that is charged with ethical significance. This is particularly so for the professional rhetorician, the lawyer who, according to White, constantly must be concerned with the possibilities of rhetoric and, correlatively, with the kind of self and community that persuasive discourse shall establish.

At first glance, White's claim may seem simple, perhaps even prosaic. But upon further reflection it grows more and more remarkable. To revive rhetoric now? Hasn't the weight of Western thought pressed out the last remnants of such a notion? Didn't Plato condemn poets and rhetorical affirmers alike, taking the latter to task for their kowtowing to the masses, and banishing the poets altogether from the ideal republic for their sin against truth, their mythic tales, and endless imitations of the real? ${ }^{64}$ Didn't Aristotle cut off poetic and rhetoric from the domain of knowledge? ${ }^{65}$ Didn't the Enlightenment teach the virtue of clear and distinct ideas, replacing the rhetorical affirmer's clamorous dependence upon a particular audience's approval with the universal audience that the authority of science commands? Haven't modern thinkers dashed vain figures of speech, condemning the empty eloquence of sententious rhetoric which seduces the ingenuous away from exact and certain truths? ${ }^{66}$ What serious thinker has time to please the public when "truth" or the "right" could be advanced instead? Are we to discard Kant's warning that the art of persuasion is "the art of deluding by means of a fair semblance," 67 that it is, in short, a form of seduction or "wooing"?68 And is it not a similar sentiment that accounts for our own century's early infatuation with the Vienna circle's symbolic logic, and our more recent attachment to eso-

63. Id. at 35-36, 44, 126-27, 161-64, 198-99.

64. See Plato, The Republic, Book X (I. Richards ed. 1966); but cf. Plato, The PhaeDRUS (W. Helmbold \& W. Rabinowitz trans. 1956) (where Plato himself relies upon explanatory myths).

65. See P. Ricoeur, supra note 20, at 31-32.

66. See M. MOONEY, VICO IN THE TRADITION OF RHETORIC 59-60 (citing Locke's reference to eloquent words as "perfect cheats"); see also E. GRASSI, supra note 29, at 18; W. BooTH, MODERN DOGMa AND THE RHETORIC OF AsSENT xiii (1974) (citing Locke's and the later empiricists' distinction between knowledge that could be called universal and permanently true, on the one hand, and the comparatively tainted field of rhetoric, which deals in degrees of belief, opinion and assent, on the other).

67. E. GRASSI, supra note 29 , at 18 (quoting Kant).

68. See W. BоoTH, supra note 66, at 137; see also Kant's critique of "popular" psychology, morality, and politics in P. RICOEUR, supra note 20, at 30, and D. VERENE, VICo's SCIENCE OF IMAGINATION 163 (1981) (noting that in the Cartesian universe, if rhetoric is not directed by truth founded on logical grounds, it becomes an instrument of power over listeners). 
teric principles whose (putatively) universalizable truths impel systematic application?6 ${ }^{6}$ Is this not persuasive evidence of a strong, historically entrenched disinclination to take rhetoric, the so-called art of persuasion, seriously as a subject worthy of respect, much less as a way of life?

Only in this context do we begin to perceive the deceptive simplicity of White's eloquent prose; only then do we begin to realize that there is far more to his claim than first meets the eye. His emphasis upon rhetoric and poetics in fact reflects a break with a Cartesian concept of reason and reasoning, a concept whose roots can be traced back to Plato and whose authority has grown so ingrained within our thinking over the last three centuries ${ }^{70}$ that to question it seems to place reason itself in doubt. ${ }^{71}$ The scientific model of truth and the Cartesian method by which certainty may be realized have until only recently captured the natural and social sciences alike. And for their part, the humanities, under pressure to adopt more rigorous (i.e., scientific) standards of knowledge, have long undergone a process of trivialization. ${ }^{72}$

Yet it seems that now our cultural mood has shifted. Cartesian certainty has for the most part become a dream. And in the meanwhile even "irrational" dreams have become a source of knowledge. ${ }^{73}$ Put differently, the quest for some Archimedean point, "some permanent, ahistorical matrix or framework to which we can ultimately appeal in determining the nature of rationality, knowledge, truth, reality, goodness or rightness"74 has become highly problematic, if not wholly illusory. As Bernstein puts it: "It is an illusion to think that there is something that might properly be labeled 'the standards of rationality',

69. See, e.g., Sherwin, supra note 4 (describing utilitarian and Kantian comprehensive views as mutually exclusive, systematically projected ideologies at work in the legal culture today).

70. See C. Perelman, supra note 5 , at 1.

71. As an example of the fear of relativism or nihilism that critical legal studies has spawned, see Carrington, Of Law and the River, 34 J. LEGAL EDuc. 222, 227 (1984):

What [the professionalism and intellectual courage of lawyers] cannot abide is the embrace of nihilism and its lesson that who decides is everything, and principle nothing but cosmetic. ... [T] The nihilist who must profess that legal principle does not matter has an ethical duty to depart the law school, perhaps to seek a place elsewhere in the academy.

72. One tends to forget that the so-called "Trivium" once embodied those three of the liberal arts which pertained to the word, or, more generally, to communication - namely, grammar, rhetoric and logic. The "Quadrivium," more congenial, perhaps, in our modern scientific age, includes arithmetic, geometry, astronomy and music.

73. See S. Freud, The InTERPRetation of Dreams 1 (J. Strachey trans. 1958) ("I shall bring forward proof that there is a psychological technique which makes it possible to interpret dreams, and that, if that procedure is employed, every dream reveals itself as a psychical structure which has a meaning and which can be inserted at an assignable point in the mental activities of waking life.").

74. See R. BERNSTEIN, supra note 30 , at 8. 
standards that are genuinely universal and that are not subject to historical or temporal change."75

But even allowing that the scientific model with its putatively universal and objective premises no longer prevails in the domain of the human "sciences," even accepting that we may no longer entertain propositions which can be systematized and measured, or determined to be certain or invariable or true by virtue of clear and distinct axioms, what, then, is to take their place?

To answer this question, we must turn to a different sense of human understanding. For example, hermeneutical philosophy, such as the one Hans Georg Gadamer has championed, rejects the classical oppositions of the Enlightenment. ${ }^{76}$ Instead of aligning science and reason on one side and tradition, prejudice, and authority on the other, this post-Cartesian viewpoint regards reason as inextricably contextualized. It can never wholly free itself from its historical context and horizons. ${ }^{77}$

Radical as this new understanding may seem, it would be wrong to characterize it, as some critics have, as intent upon deprecating reason, or inviting moral (along with epistemological) relativism. ${ }^{78}$ To the contrary, the effort here is to use our powers of self-reflection to come to grips with human finitude; to treat human affairs realistically in light of practical reason (or phronesis) rather than mythically, as if scientific reason (or episteme) and the method of technology could suffice to guide and inform human actions. ${ }^{79}$ This means that in place of certainty, of judgments that are either right or wrong according to clear and distinct axioms or first principles, we endorse the fundamental openness of understanding. In this sense, openness supplants proof with persuasion, and logical necessity with self-reflective interpretation.

Correlatively, one also encounters here a return to Renaissance themes: the enhancement of individual autonomy, freedom, and dignity. For once we view human understanding as proceeding on the

75. Id.

76. See H. Gadamer, TRUTH AND METHOD, supra note 13.

77. Id. at 241-58. See also J. Dewey, Reconstruction IN Philosophy 96-97 (1948): The plans which are formed, the principles which man projects as guides of reconstructive action, are not dogmas. They are hypotheses to be worked out in practice, and to be rejected, corrected and expanded as they fail or succeed in giving our present experience the guidance it requires. ...

In contrast with this experimental and re-adjusting intelligence, it must be said that Reason as employed by historic rationalism has tended to carelessness, conceit, irresponsibility, and rigidity - in short absolutism.

78. See Carrington, supra note 71.

79. See H. GADAMER, TRUTH AND METHOD, supra note 13, at 415-17; R. Bernstein, supra note 30 , at $38-40$. 
basis of interpretive judgment rather than logical necessity, it no longer seems so imperative to fit the individual into some larger, abstract system. ${ }^{80}$ Instead, the individual assumes an active role in a more open-ended kind of discourse - the discourse of rhetorical persuasion. This, in turn, reduces the depersonalization usually associated with modern social science. In the realm of rhetoric, the play of images or metaphors, the force of narrative and characterization spur the individual's conviction, belief, commitment. Eschewing universals, rhetorical discourse takes as its point of departure the specificity of needs and desires which particular dramas concretely embody. ${ }^{81}$ In brief, from this perspective abstract logic yields in priority to concretely contextualized rhetoric. ${ }^{82}$

In the face of this epistemological turn, White's advocacy of a constitutive rhetoric, built as it is upon metaphor rather than category or concept, ${ }^{83}$ fits well within the new theoretical currents. ${ }^{84}$ The "postmodernist" moment in philosophy, social theory and literary criticism, and its significance for the legal culture are topics that have been canvassed at length in recent legal scholarship. ${ }^{85}$ Suffice it to note here that scholars, including legal scholars, who have explicitly questioned the rational tradition of the Enlightenment have had to face serious charges, including allegations of moral relativism, nihilism, and anar-

80. See, e.g., F. DOSTOEVSKY, Notes From Underground 23 (R. Maitlaw trans. 1960): One's own free unfettered choice, one's own fancy, however wild it may be, one's own fancy worked up at times to frenzy - why that is the very most "advantageous advantage" which we have overlooked, which comes under no classification and through which all systems and theories are continually being sent to the devil.

81. See E. GRASSI, supra note 29, at 7. "The metaphor is, therefore, the original form of the interpretative act itself, which raises itself from the particular to the general through representation in an image, but, of course, always with regard to its importance for human beings." "The conformity of reality to human needs comes about through human work, and this occurs through the conveyance of meaning ... not in the frame of universal, abstract, rational language." Id. at 100. See also J.B. White, HERACLES' Bow, supra note 5, at 35-36 ("IT]he lawyer responds to the felt needs of others ... . Law always operates through speakers located in particular times and places speaking to actual audiences about real people.").

See also P. RICOEUR, supra note 20 , at $257-313$ (tracing concepts to specific metaphorical origins and suggesting that metaphors raise corresponding concepts, literally serving as their foundation).

82. E. Grassi, supra note 29 , at 24-34.

83. See J.B. WhITE, HERACLES' Bow, supra note 5, at ix, xi-xiv; see also White, Thinking About Our Language, 96 YaLe L.J. 1960, 1968 (1987):

"Concepts" are not words; they are the internal or intellectual phenomena that words are thought to label, as markers, or towards which words are thought to point. To talk about concepts is thus to take a step in the direction of talking as if words have no force of their own, as if they are transparent or discardable once the idea or concept is apprehended.

See also D. VERENE, supra note 68 , at 34-35, 80-81.

84. The impetus behind the new attitude has been traced to figures such as Nietzsche, Kierkegaard, Freud, Heidegger, Gadamer, and Derrida. See D. VerenE, supra note 68, at 32.

85. See, e.g., Boyle, supra note 19; Brosnan, supra note 19; Rubin, The Practice and Discourse of Legal Scholarship, 86 Mich. L. REV. 1835 (1988). 
chy. ${ }^{86}$ Some of those who touch upon these highly controversial topics, particularly writers associated with the Critical Legal Studies movement, have done little effectively to offset these allegations. Indeed some have even embraced the charges that have been leveled against them. ${ }^{87}$ For his part, White seems to escape this controversy - but at a price yet to be fully reckoned.

Despite its intimate connection with abstract and volatile themes, White's text nevertheless remains thoroughly, even adamantly, untheoretical in tone and substance. The clarity and simplicity of White's prose are great virtues, for they invite broad access with little interference from the kind of esoteric abstractions which plague (sometimes with almost gleeful abandon) so many post-modernist texts. Significantly, White's work does not simply belie deeper and more difficult theoretical issues. While these may be implicated, their consideration is unnecessary to the accomplishment of the task White has set himself in his recent work. That task is to raise up rhetoric from its maligned status as persuasion for the sake of persuasion. The means by which White seeks to revitalize the field of rhetoric are expressed and intentionally modeled by the way in which his own "constitutive" rhetoric works in practice. White's essays embody the art he acclaims. But this virtue, and the deceptive simplicity of its configuration, point up a hidden vice: the possibility of deception, which always lurks within rhetorical persuasion. For rhetorical persuasion sometimes succeeds precisely by taking the other in, deflecting her on unacknowledged, perhaps deliberately hidden grounds.

I contend that the issue of deception must be faced head on before the rehabilitation of rhetoric can proceed apace. There is a paradox here. It resonates within the overdetermined meaning of the phrase "being taken" (or "taken in") by the other's words. ${ }^{88}$ Interpreting this paradox will bring before us the complex relationship between naked or unjustified power and legitimate authority. ${ }^{89}$ It is, I believe, an is-

86. See Eastland, Radicals in the Law Schools, Wall St. J., Jan. 10, 1986, at 16, col. 4; Carrington, supra note 71 , at 227.

87. See, e.g., Kelman, supra note 23, at 327 n.84; Singer, supra note 23, at 6; Tushnet, Following the Rules Laid Down: $A$ Critique of Interpretivism and Neutral Principles, 96 HARV. L. REV. 781 (1983).

88. The issue here can be expressed by the query: Where is the other taking me, and do I really want to go? Or, do I even know that I've been "taken?" The overdetermination of the word "taken," therefore, turns upon the cunning aspect of the word -I am both taken by (willingly, if not entirely knowingly), and taken in by (unwillingly and unknowingly), the word's charming effect upon me.

That which obliges my response against my will and without my knowledge, lacks my consent. Therein lies its coercive force. Cf. Sherwin, supra note 4, at $781 \mathrm{n} .181$.

89. See Sherwin, supra note 43 , passim. 
sue which warrants particularly close attention in the context of a rhetoric and poetics of law. In this field, unlike literature, the power of discourse claims more than a reader's imagination; the language of the law often acts upon particular individuals whether they will it or not. Thus we must ask, what is the appropriate source of authority for persuasion? If, unlike science, there is no universal audience to whom the rhetorical affirmer can appeal, the question emerges, to which audience (or rhetorical community) is it proper to appeal? Nor is it clear exactly how persuasive the law should be in the first place. For example, to what extent must the effort to achieve consensus, for the sake of compliance and social harmony, overrule commitment to, say, constitutional principle? As history has shown, interpreting such principles often yields unpopular results. How then do we square the court's counter-majoritarian role with the art of persuasion? (Or, put differently, how do we justify privileging esoteric policy or constitutional analysis over ordinary language?) ${ }^{90}$ Are there some audiences that the courts, in preparing and presenting their rhetoric, may legitimately leave out - or only pretend to include? ${ }^{91}$ Without theory to help explain and justify the exercise of power, questions such as these will continue vainly to press upon us for adequate answers. ${ }^{92}$

The aversion to theory ${ }^{93}$ that characterizes White's work must be overcome. More specifically, to the extent that White equates abstract theory and concept-formation in general with a form of illusory discourse, or lifeless grammatology, ${ }^{94}$ he thereby unduly displaces the steadying and clarifying function of speculative discourse. ${ }^{95}$ As an al-

90. See, e.g., Tushnet, Anti-Formalism in Recent Constitutional Theory, 83 MICH. L. REV. 1502 , 1532-34 (1985) (arguing that intuitionism fails as a theory of constitutional reasoning because such a theory cannot adequately explain why any particular person's intuitions should control).

91. See Sherwin, supra note 4.

92. This goes to what I refer to as the need to project regulative ideals reflectively as a basis for judgment. See generally Tammello, supra note 52, at 341 n.17.

93. See J. ELY, supra note 10.

94. See White, supra note 83 ; $c$. S. ToulmIN, supra note 51 , at 71.

95. White's own, apparently "pre-reflective," assumption of a Kantian perspective, endorsing "the ordinary-language practice of blaming" in opposition to utilitarian cost/benefit or means/ ends calculation, evidences the ineradicability of theoretical assumptions - even in our "ordinary" language. See J.B. WhITE, Heracles' Bow, supra note 5, at 192, 195 n.1, 211 ("[T] criminal law proper concerns itself only with instances of violation, and these should be punished only as blame requires, never for exemplary or deterrent reasons."). Cf. Sherwin, supra note 4, at 739-43 (noting that upon reflection the putatively atheoretical nature of ordinary language, like the naive, self-evident truths of ordinary common sense, belie deeper complexities; deceptively simple common-sense truths may be viewed as social constructions of meaning which are traceable to particular presuppositions or perspectives, as well as to specific histories, inherited texts, and local experiences). See also P. BERGER \& T. LuCKMANN, supra note 51.

Therefore, contrary to White's position, it is far from clear, much less self-evident, that the Kantian presumption (that the individual never be treated as a means to an end, but only as an 
ternative, we may view interpretive practice as functioning at the intersection of both rhetorical (or figurative) and conceptual (or speculative) discourse. ${ }^{96}$ From this position, while the danger of lifeless conceptualization may be checked by rhetoric's vitalizing images, the multiplicity and polysemy of figurative utterances may be checked by the clarifying and systematizing force of critical theory. ${ }^{97}$

According to this "dialectical" approach, therefore, whether the putative source of authority by which an interpreter warrants the validity of a particular judgment derives from the heuristic norms of critical theory or the compelling figures of rhetorical utterance, the burden of persuasion remains the same. In both cases the interpreter must be able to appraise and assess the worth of his or her claims. This means that she must be able to articulate persuasively, to make clear to herself and to the other who is being addressed the implicit reasons that explain and justify endorsing one position as opposed to another. In this way, the gulf of misunderstanding that separates incommensurate forms of discourse may be crossed.

In short, it is important to understand the normative and theoretical implications of unduly curtailing a particular type of discourse whether the discourse in question is that of critical theory in general, or its rational (Kantian) or empirical (utilitarian) manifestation in par-

end in himself) should in all cases trump utilitarian calculations. Indeed, judicial prudence, such as the court's concern with public compliance or its assessment of deterrence as a tool of crime control, is likely to ensure that pragmatic calculations will not be jettisoned from the lawyer's or judge's rhetorical repertoire. See, e.g., Kronman, supra note 24 . Nor is the rhetorical affirmer unaware of this reality. Recall, for example, the careful rhetorical attunement between speaker/ writer and audience that lies at the forefront of the art of rhetorical persuasion. See ARISTOTLE, supra note 3 . White's sensitivity to the relationship between narrative and audience shows that the legal rhetorical affirmer is no exception to this general practice. Note, for example, the shifts in White's own prose in J.B. WHITE, HERACLES' Bow, supra note 5, depending upon whether he is addressing legal scholars (chs. $5 \& 9$ ), law students (ch. 3), lay teachers (ch. 4), or literary critics (chs. $7 \& 8$ ).

In any event, the virtues or desirability of a Kantian, or anti-utilitarian, viewpoint must be refiectively explained and justified, it cannot be posited as self-evident from the start, or championed as something that is embedded within our everyday language without further proof.

96. See P. RicoeuR, supra note 20 , at 302 ("Interpretation is the work of concepts. It cannot help but be a work of elucidation, in the Husserlian sense of the word, and consequently a struggle for univocity.").

97. In other words, the deconner's skill at uncovering the deadened metaphor that may lie hidden in traditional abstract theory or text-bound interpretive practices is not enough. The hard task that the critical theorist must confront is to reconstruct compelling normative ideals or models that will advance us beyond the stage of critical nihilation. It is this task of reconstruction that theorists such as Unger and Habermas are now undertaking.

For their part, the rhetorical affirmers face a similar charge. It is not enough to uncover the power and figurative complexity of ordinary language. It is also necessary to generate or restore compelling images, root metaphors, or topics of argumentation which will enliven contemporary discourse and normative debate. See supra note 39; see also H. GADAMER, TruTH AND METHOD, supra note 13, at 146 (on transforming the dead trace of inherited, text-bound meanings back into living meaning). White's endeavor is currently contributing to this objective. 
ticular, or the discourse of figurative rhetoric. Indeed, in the absence of adequate self-reflective explanation and justification, White's own rhetoric risks turning into the kind of seductive ensnarement that has long plagued the field of rhetoric, leading a once high art into desuetude.

With these critical themes in mind, let us take a closer look at White's claims on behalf of constitutive rhetoric. White's work works in the way that rhetoric works best. It takes us in almost unawares. As we shall see, the "almost" is pivotal. For unless we enjoy some awareness of the process of persuasion, we can hardly feel confident that we have been persuaded of anything. Besides, people need, and therefore seek, reasons to believe. At the same time, however, an awareness of persuasion's force in no way guarantees that the actual source of its effect has been expressly conveyed. Indeed, our willingness to yield to the text may alter if we come to realize that our submission was a function of the text's "seduction" or deceit - as opposed, say, to its logic, or its common sense, or its urging to do what is "right" in principle. The question this raises is the following: if taking something as a basis for belief presupposes a decision as to whether the proffered reason is tenable or should be rejected out of hand, ${ }^{98}$ what of those occasions when the text succeeds in deceptively taking us, on grounds which remain hidden from view? Moreover, even were we to recognize the reasons for belief that a given text offers, on what occasions do we permit one type of persuasion to take us in, and another to fail?

To answer these queries in the context of law, we must concern ourselves with privileged forms of persuasion, what Ackerman has referred to as "official languages of power" within our legal culture. ${ }^{99}$ Concomitantly, we must grow alert not only to what the other tells us, but also to whether we are being taken in by a feint. As practicing attorneys and judges well know, oftentimes in order to induce acceptance of a particular argument or judgment, it is useful to employ an "acceptable" mode of persuasion. So, a party may ("prudently") hide particular reasons which, while in some way controlling, if honestly expressed might well put the other off, striking him or her as an unacceptable basis for persuasion. ${ }^{100}$

98. Or masked if it cannot be directly embraced. See, e.g., Roe v. Wade, 410 U.S. 113, 14764 (1973) (where a putatively neutral scientific analysis seeks to circumvent the normative controversy before the Court).

99. See B. ACKERMAN, supra note 39, at 3.

100. Cf. Sherwin, supra note 4 (describing the use of putatively neutral cost/benefit analyses to mask ideology, such as the preferred policy of crime control). 
Thus the problem with legal rhetoric emerges early. Speaking about persuasion directly risks exploding persuasion's seductive power. As with a novel that insists upon challenging its own premise - for example, by directly reminding the reader of its fictional content ${ }^{101}$ - the reader's willing suspension of disbelief will eventually grow strained, if it continues at all. ${ }^{102}$ On the other hand, forestalling dissuasion by means of deceptive discourse has risks of its own. For example, repeated use of deception threatens to lead us to a situation in which we find ourselves constantly seeking to pull the curtain on speech, in search of some charlatan $\mathrm{Oz}$ behind the veil of discourse. Fabricating accommodation among conflicting normative commitments will also prove unavailing. In the process, controversy may be avoided, but this may only succeed in emptying judgment of any real content. As a result of this failure of nerve, the particular controversy at issue, and the accompanying rift in the social fabric, remains intact. And such a situation can only invite future conflict. ${ }^{103}$

White's emphasis on our role as creators of community distinguishes his project from one concerned about speaking and writing solely for their own sake. So, on the way to persuasion, White has us first reflectively encounter the ethical responsibilities incumbent upon co-creators of self and community. White does not take us in unawares regarding the character- and culture-building power of persuasive speech. Indeed, his chief goal throughout is to make us view with increased clarity and respect the creative potency of our discourse. In the process, he also seeks to move us from what he sees as a widespread predisposition in our current legal culture: the tendency to view law as merely an instrument for achieving preferred ends. White rejects a conception of law as a closed system of abstract, antecedently defined policy goals. Instead, he would have us view the legal process as an open hearing that strives for equal conversational access.

For White, instead of abstract policy guidelines, concrete contextualization - assessing litigants' specific needs and desires under specific circumstances - should mark the court's point of departure. Rather

101. See, e.g., I. Calvino, If on A Winter's Night a Traveler (1979).

102. Whether inspired by fiction writers or CLS critics, hyper-self-consciousness about persuasion itself threatens to take us to meaning's vanishing point. From this perspective, all rhetoric comes to be seen as diverting arabesques, fanciful lines that draw us in only to leave us stranded in empty spaces afterwards.

103. Cf. Smith, The Critics and the "Crisis": A Reassessment of Current Conceptions of Tort Law, 72 CORNELL L. REv. 765 (1987):

A victim's sense of injustice does not amount simply to an irrational need to strike back at a wrongdoer; rather, it represents the victim's consciousness that the normative order upon which the victim has relied has been threatened, and that if the norms constituting that order can be breached with impunity then they will lose their meaning and force. 
than presuppose - and hence, privilege - any particular policy, the court should attend to the facts of the case at hand. This requires a hearing that does not mechanistically conform particular outcomes to a strict conceptual schema. Rather, the decisionmaker must listen and do justice to both parties; she must find that integration, that persuasive synthesis, by which justice is done in fair view of both sides of the issue or issues raised. ${ }^{104}$

White wants us to change our minds. He wants his text to convince us of his view of judging. But he does not aim to take us in wholly unawares. He tells us how the change is to be achieved. By reading texts, he explains, the reader opens herself up to the possibilities of self and community which the text creates. Persuasion, in this sense, is not a matter of command. Authorial power must be "artistic" if it is to work. ${ }^{105}$ For example, when we are presented with characters with whom we can identify or types of community to which we can imagine ourselves belonging, we can experience for ourselves other possibilities of self and ways of being among others. In seeking to understand the discourse (the text or speech) of the other, we give ourselves over to what is being said. Not by abstract force or command or the empty play of pleasing distraction are we held by the other's words; rather it is by the drama of events, by character and plot. As White succinctly puts it: once we get the voice right, all else that matters will follow. 106

Persuasion, says White, proceeds as a matter of voice. What then is this voice? In ancient times perhaps one would say it is the gift of the Muses - a gift that mortals could neither cast away nor confidently interpret. ${ }^{107}$ It was said to be the "gift" of logos, 108 the speech or narrative or tale that somehow intertwines entertainment and healing, that might speak things as they are, or might as readily personify the son of eris - embodying such evils as strife, falsehood, and dispute. ${ }^{109}$ For it was held in ancient belief that the Muses often tell lies that look like truths. ${ }^{10}$ And indeed "persuading" (paraiphamenoi) in the ancient Greek carries the sense of "speaking to deflect," "to 'deviate' someone." It often connotes an act of bending the mind or will

104. See J.B. White, Heracles' Bow, supra note 5, at 35-37.

105. Id. at xi.

106. Id. at 135 .

107. See P. Pucci, Hesiod and the Language of Poetry 2-3 (1977).

108. A mixed one at that. See id. at 82-115 (on Pandora).

109. Id. at 4-5.

110. Id. at 9. 
of the other, ${ }^{111}$ of turning someone away from his own line of thinking. ${ }^{112}$ Such persuasion is sweet, like-honey. Poetic speech (with its honey-like words) has been characterized metaphorically as possessing "a liquid, viscous quality." 113 Yet, by sweetening, the poet also distorts the truth. Indeed, the healing quality of the word may even stem from this power to soften truth - thus opening the way to peace from strife, a form of enchantment that leads to oblivion. ${ }^{114} \mathrm{It}$ is the same enchantment that acts as a dolos, or trick. ${ }^{115}$

But according to White it is not the paradox of speech, its ability to deceive, to double back upon itself as either a source of truth or deviation, that the "voice" of the professional rhetorical affirmer represents. The rhetorical voice White describes possesses nothing of the failed metaphysics by which the poet Hesiod claimed "divine authority" willfully converting his own logos to universal mythos (or true narrative). ${ }^{16}$ Only by such poetic license could Hesiod seek to overcome the suspicion that it is he and he alone who has contrived truth according to his own measure. For White, however, the voice connotes none of this. It is meant to convey "the character of the speaker," the "sense of self, language and audience." If we are to inquire further what White means by "character," "language," or "audience," we can do no better than to turn to that text which, according to White, "frames [his] book as a whole," 117 namely Sophocles' Philoctetes. Here we will find the unifying force that sustains White's vision; we will find as well the partially hidden voice that, in interpreting Sophocles, generates its own persuasive field - weaving the design of the narrative into which the reader is to be taken. ${ }^{118}$

According to White's reading of Sophocles' play, the nature of character, language and community emerges in opposition to dolos, or

111. Id. at 17 .

112. Id. at 25 .

113. Id. at 19.

114. Id. at $21,29$.

115. Id. at 94. Indeed, Pucci takes Pandora as the first rhetorical figure, marking the beginning of rhetoric. Id. at 100 .

116. See Isocrates, supra note 3, at 333 (lines 264-68) (warning of the dangers that accompany over-indulgence in metaphysical speculations, those "barren subtleties" which allow the mind to be "dried up").

117. J.B. WhITE, HeRaCles' Bow, supra note 5, at 3.

118. Cf. M. Detienne \& J. Vernant, Cunning Intelligence in Greek Culture and SocIETY 3 (1978) (describing metis [or "cunning intelligence"] as a "complex but very coherent body of mental attitudes and intellectual behaviour which combines flair, wisdom, forethought, subtlety of mind, deception, resourcefulness, vigilance, opportunism, various skills, and experience acquired over the years"); see also id. at 27 (noting the "most prized cunning of all: the 'duplicity' of the trap which always presents itself as what it is not and which conceals its true lethal nature beneath a reassuring exterior"). 
trickery. But I shall claim that this assertion is more difficult to sustain, more riven by paradox, than White seems willing to acknowledge. Only by admitting the paradox of persuasive speech, by facing directly and self-consciously the shadow of eris (discord, strife, and deception), may the power of rhetoric be safely harnessed. After describing Sophocles' drama, and then White's interpretation of it, I shall counter with another interpretation - one that places at dead center the strange way in which the "almost" qualifies the way rhetoric takes us in. For I believe that the authority and nature of the reasons with which White supports his interpretation of the Philoctetes may be questioned. And in the process of questioning, a critical dimension of the rhetorical "voice" hidden in White's text will come to light.

In White's reading of Sophocles' play, we shall find the means by which to assess the deceptive simplicity of White's voice, and perhaps also the basis for an even richer interpretive yield. For between White's persuasive rhetoric (the words that take us in) and the unspoken voice (the persuasive power of plot and characterization which operate beneath the surface of the text), there is much to speak of. Taken in almost unawares, we are left to wonder: what is it that we are being told, and what yet remains unknown, hidden in the author/ speaker's effort to win our belief?

The story of Philoctetes as Sophocles tells it may be summarized as follows:

For ten years Philoctetes has been living alone on an uninhabited island in the Aegean. The Achaeans, on their way to Troy, exiled him there because of the offensiveness of a foul-smelling and festering wound on his foot. Philoctetes received the wound when, having unwittingly trespassed upon sacred ground, he was bitten by a serpent. We are told that the Greeks cast him out because his cries of pain prevented the others from making proper sacrifices and libations. Philoctetes has survived during his years of exile only because he has with him the wondrous bow and arrows of Heracles, a demi-god, who gave them in return for a kindness done - Philoctetes lit his funeral pyre. These weapons possess a special power: they never miss their target. Now the Achaeans, led by the wily Odysseus - who was among those who cast Philoctetes into exile ten years before - have returned for him. A soothsayer, whom the Achaeans recently captured, has told them that Troy will not be taken without Philoctetes and his god-given bow. Accompanying Odysseus on this mission to procure the service of Philoctetes' bow is Neoptolemus, the well-bred 
but hardly experienced son of the great warrior, Achilles. ${ }^{119}$

According to White, Sophocles' drama tells us how the type of discourse particular speakers choose constitutes both character and community. Two types of discourse in particular are set before us. One type seeks to persuade by trickery, taking the other in by deceitful stratagem, or manipulative plot (dolos). The second type of discourse proceeds in sharp contrast to the first. It seeks to persuade by openly and sincerely engaging the other as an equal and a friend, giving reasons in support of a desired end or course of action. White characterizes the latter way of speaking as true persuasion (peitho). According to White, in the legal culture today, particularly in the area of criminal law, it is by dolos or instrumentalist reasoning - treating the other as a means to an antecedently defined purpose or end - that judicial decisionmaking proceeds. ${ }^{120}$ White reads the story of Philoctetes as a model or a paradigm that teaches us to see the wrongness of dolos as a way of life (i.e., as a way of speaking to and being among others in society). Correlatively, it also teaches the need to learn peitho.

Deceitful manipulation appears in several forms in Sophocles' drama. At the outset, Odysseus tells Neoptolemus to "ensnare the soul of Philoctetes with your words."121 Appealing to Neoptolemus' sense of patriotism and personal pride, Odysseus tells Neoptolemus that the fall of Troy and the occasion for Neoptolemus' own proof of valor cannot take place until Philoctetes' bow is taken. This appeal convinces Neoptolemus, against the latter's better instinct, to practice upon Philoctetes "craft rather than persuasion."122 There is no other way to succeed, Odysseus says. And so Neoptolemus complies. Giving himself to Odysseus' instrumentalist goal, he becomes an agent of instrumentalist practice. (Says Odysseus: "When one does something for gain, one need not blush [with regard to the means chosen.]"123)

Converted to Odysseus' stratagem, Neoptolemus proceeds to ensnare Philoctetes in a tale made up for the occasion. He wins Philoctetes' trust by claiming also to have suffered at the hands of Odysseus. By this "plot" Neoptolemus succeeds in establishing a (false) basis for sympathy, trust and friendship between himself and Philoctetes. And the ruse works. When Philoctetes is overcome by the agony of his wound, he entrusts his bow to Neoptolemus' safe keeping. With victory at hand - for Philoctetes is now helpless - Odysseus enters

119. See J.B. White, Heracles' Bow, supra note 5, at 6.

120. Id. at 194-99, 203-11.

121. SOPHOCLES Philoctetes in SOPHOCLES II 197, lines 56-57 (David Grene trans. 1957).

122. Id. at 199-200, lines 79-122.

123. Id. at 200 , line 111 . 
upon the scene, ready to collect the prize of his (and Neoptolemus') wile. At this point, however, an unforeseen obstacle comes into play. Neoptolemus feels compassion for the long-suffering Philoctetes. Moved by a renewed sense of "justice," he throws off the way of guile. Refusing to hand the bow over to Odysseus as the latter vainly commands, Neoptolemus now resolves to persuade Philoctetes with good reasons, as friend to friend, that Philoctetes should return with them to the plains of Troy. Thus, upon Philoctetes' return to consciousness, Neoptolemus reveals to him the trap that had been laid, but urges Philoctetes to help the Greeks anyway, for his own sake: for it is prophesied, Neoptolemus recounts, that Philoctetes' return will not only lead to his cure (in the hands of the Asclepiadae), but also to his glory. Says Neoptolemus: "[T]hen with the bow and by my side, you will become Troy's conqueror." 124

But Neoptolemus' sincerity now is unavailing. Philoctetes' faith in the Greeks has been irrevocably shattered by this additional evidence of their trickery and cruel manipulation. He will not be persuaded. Indeed, he can only wonder what future evils he may suffer at the hands of his former countrymen. Taking advantage of Neoptolemus' change of heart, Philoctetes sets him along a different path. He beseeches Neoptolemus to end the long exile by taking Philoctetes back to Oeta, his native land. Standing up to Odysseus' threats, Neoptolemus hands the great bow to its true owner, and assents to Philoctetes' request. And so things would end but for the sudden appearance of Heracles himself, who commands Philoctetes to obey Necessity. ${ }^{125}$ For as it turns out, his fate - as had been foretold - is to be cured of his suffering and to conquer Troy at Neoptolemus' side.

According to White, the lesson of the play is clear. Sophocles teaches by leading us first to identify with Odysseus and his cunning use of the young Neoptolemus' innocence and credulity. He then has us experience the despicable use of Philoctetes by Neoptolemus. Finally, Sophocles has us identify with Neoptolemus' realization of what is "right" - namely, to turn away from deceit (dolos) and instead to embrace the practice of true persuasion (peitho). We see in this, White maintains, how the formation of character and community follows upon the ways in which we choose to speak to others: i.e., either as to a friend and equal, or as to a "means to an end," an impersonal object to be manipulated in the service of one's own preferred goals. In White's view, then, the meaning of Sophocles' drama, as with all rhet-

124. Id. at 249, lines 1334-35.

125. Id. at 252-53, lines 1408-48. 
oric, is to be found in the effect it has upon its audience. The ideal reader, writes White, encounters honor and dishonor, shame and justice, community and deceit, as a result of his or her identification with the characters and the community they create by their discourse. ${ }^{126}$

In White's view, the "central value of this play is integration: the putting together of parts of the self, parts of experience, parts of language, into meaningful wholes."127 It teaches, he says, the value of freedom and autonomy - as against dominance by deceitful manipulation. It brings us to realize that "the only imaginable attitude to take toward persuasion and community is that of recognition and integration, the only imaginable rhetoric is sincere and authentic (peitho, not dolos)."128 In short, the play achieves between reader and text a community that parallels the one that emerges between Philoctetes and Neoptolemus. In White's words: "[A]s we hear Philoctetes speak, we respond to him as Neoptolemus does; we respond to Neoptolemus as Philoctetes does; and so on."129

In this we see the paradigm for White's entire book. For it is White's claim throughout these essays that neither conceptual schemata nor abstract theories - with their rigid and imageless definitions and their abstract, systematic categorizations - can teach us what literature can by force of dramatic example. By fostering through characterization and plot the ideal reader's identification with character and community, the text, including the literature of the law, creates character and community. And it does this not by virtue of the dictates of logical systems or subjective instrumentalist talk, but rather through egalitarian colloquy. For if the reader or listener is to be persuaded, White seems to be saying, she must be led to decide for herself, to be persuaded as a friend: as an autonomous agent, rather than as a person within someone else's abstract conceptual system.

Thus we find that for White the Philoctetes serves multiple purposes. It not only teaches us to change our minds (i.e., to move away from the endorsement of instrumental reasoning and discourse), it also teaches the method by which that change is to occur: by sincere and persuasive rhetoric or storytelling. In other words, according to White's reading, not only does Sophocles' play get the message right, it also instructs us as to the proper way of hearing and proclaiming (and concretely embodying) that message as a discursive practice.

126. J.B. White, Heracles' Bow, supra note 5, at 25.

127. Id. at 21.

128. Id. at 25 .

129. Id. 
This is the cue for the form of discourse that White defends in opposition to "systems design" talk, for it describes the art of persuasive (or "constitutive") rhetoric. Only by experiencing for ourselves the possibilities of character and community, according to White's interpretation of Sophocles' exemplary text, can we appreciate fully what a given text (be it ancient drama or contemporary judicial opinion or legal argument) is asking us to become, and what kind of community it is thereby calling into existence.

Putting the matter succinctly, White claims that practicing the art of rhetoric (professing the law as lawyer, judge, or scholar) is a matter of "voice." Within his invocation of the power of voice, White includes the language the individual chooses to speak, the sense of self she projects, and the type of community her discourse and her discursive engagement with the other create. ${ }^{130}$ It is by the power of voice, then, that narrative (or any discourse for that matter) achieves coherence. The unity of the text or discourse consists in the writer/ speaker's vision of self, others and community, the images, characterizations and dramatic interactions she uses, and the way she emplots these elements as a whole.

Granting that voice operates as White says it does, our appraisal of its works yet remains an open question. For example, if self emerges out of cultural and personal histories, if it reflects those texts and dramas which we inherit from the past, how are we to know that the voice we choose is our own? How are we to step out of the community of texts or discourses that shapes and informs who we are? By what signpost are we to recognize that language which is ours and that which is the other's? Lacking critical distance, we cannot gauge the search for our voice in relation to the other's. White's characterization of voice also raises a related difficulty: the problem of judgment. The question here is, how are we to assess the texts and discourses that we inherit, that make us what we are? By what standards are we to judge the possibilities of self and community that inherited texts and discourses hold out? ${ }^{131}$

To help us interpret, and thus also to refine or create anew in our own rhetorical practices, the meanings of self and other that we inherit, White offers such guiding values as "integration,"132 "autonomy,"133 and "freedom."134 These overlapping standards, it must be

130. Id. at $45-48$.

131. Id. at 228. Cf. R. BERNSTEIN, supra note 30, at 107.

132. J.B. White, HeRACLes' Bow, supra note 5, at 10-11, 21-24 (describing integration as the cultivation of a fuller, more reflective and responsible sense of self).

133. Id. at $36,42,131$ (opposing deceitful manipulation or "disintegration" at the hands of 
admitted, are hard to oppose. But so too are they hard to pin down with any precision. For example, one can easily imagine the practice of persuasive rhetoric leading to many different places, to many different kinds of character and community, in the name of the same general values. ${ }^{135}$ What guidance then do they really provide?

In this context we return to the title essay in White's text, Heracles' Bow: Persuasion and Community in Sophocles' Philoctetes. White's choice of title now strikes us with renewed force. For it becomes apparent that White has anticipated and signaled his book's unity of purpose and method in his reading of Sophocles' great drama. With this stroke, however, White also conveys the limitations inherent in his approach.

In what follows, I shall not challenge on his own terms White's particular reading of Sophocles, or his explanations of what "reading" is in general. Indeed I welcome and highly esteem White's contribution to those of us in the legal culture who are seeking a way of deepening our understanding of ourselves and our practice as professional jurists. I am persuaded that White's constitutive rhetoric provides a model for legal discourse that is far richer and comports far better with our democratic traditions than the systems design talk and instrumentalist calculations which have come to dominate large areas of the current legal culture. Yet I also believe that there is more to the art of rhetoric than White explicitly describes - even as there is more to Sophocles' drama than White's reading allows. To make this claim clearer, the latent designs (or unspoken plot) of the authorial voice that unifies and empowers White's text need to be considered more closely.

In the following part, I propose that the suspension of disbelief and personal prejudice by which we allow ourselves to be taken in by what the text says should itself be suspended by critical reflection, and that this critical gesture be included as an essential component of interpre-

the other, while also self-refiectively finding one's self in the narrative (language, text, story) of the other; taking direct responsibility for the culture- and community-building effect of speaking in one particular way as opposed to another).

134. Id. at 30-31, 47, 124 (choosing one's own discourse, finding one's own voice and character in a context of "openness" or "many-voicedness," rather than becoming a cipher within another's abstract system).

135. For example, Kantian deontologists and Nozickian libertarians alike might well espouse the virtues of integration, autonomy and freedom - to utterly disparate ends. See P. CoRBETT, supra note 26 , at 56 :

Freedom, says the Marxist, consists in the mastery of nature and society; religion is a slavery to human weakness. Freedom, says the Catholic, consists in obedience to God; mastery of the world is slavery to man's assertive pride. It is as if two doctors could not agree as to what is to be counted as an illness. 
tive judgment. Only with this move - a move I characterize as "suspicion" - can we come to grips with the unspoken "plot" that operates within every interpretive judgment, a plot that takes us in more or less unawares. This critical move brings to light the manipulative thrust of White's own constitutive rhetoric and our own ensnarement within it.

\section{The Critical Gesture: Revealing the Plot}

In what follows, I take Sophocles' drama, and White's reading of it, as paradigmatic. While I do not take issue with the terms that define the particular reading that White offers, I believe his claim that this is the only reading available to us can (and should) be challenged. In taking up this challenge, I hope to bring out not only the need to complement White's reading with additional interpretations, but also to highlight the essential role of the type of critical gesture that makes those additional interpretations possible. In this sense, the critical gesture I offer takes on a paradigmatic aspect of its own.

At the core of White's text is a belief that there is a better way to think and talk about the practice of law than the calculative, systems design talk that now dominates much of the legal culture. Rather than reduce meaning to abstract conceptual schemes or conveniently encapsuled messages, White's notion of constitutive rhetoric opens out to the richness of concrete conflicts among particular individuals. ${ }^{136}$ By proposing that we think of the practice and process of law as a form of rhetoric, White underscores the importance of treating the specific needs that particular individuals present in particular concrete controversies. Rhetoric traditionally has expressed this sensitivity to specifics by emphasizing the need to appreciate to whom one is speaking. Hence we witness White's concern with audience. ${ }^{137}$

White's suggestion that law may also be viewed as a form of poetics works toward the undermining of putatively unified, comprehensive, and abstract conceptual schemas. Such schemas tend to reduce particular individuals to impersonal ciphers within the larger whole, or system (as, say, units of "utility" that can be aggregated and maximized). ${ }^{138}$ In this way, White's talk about the poetics and rhetoric of legal discourse embraces a plurality of voices. ${ }^{139}$ Concomitantly, it embraces the uncertainty that accompanies encountering and judging

136. See J.B. White, HeRACLES' Bow, supra note 5, at 83-89, 95.

137. Id. at $172-73$.

138. Id. at $30-31,198-99$.

139. Id. at 124 . 
the discourse of others - especially when confronted with competing discourses. This approach provides an alternative understanding of doing justice. Rather than simply locate the right theory, foundational concept, or most pressing social need, the decisionmaker must find the right integration of the concerns expressed by opposing parties and choose the best language in which to convey her proposed accommodation. ${ }^{140}$

But how does one tell the right story with the right voice? At least part of the answer emerges, White claims, when we come to appreciate more fully the kind of self and community the decisionmaker creates by the way she chooses to speak. Indeed, White seeks precisely to enhance our understanding of the power and art of rhetorical persuasion by examining how it works both to resolve particular disputes and to help create self and community. And, as we have noted, Sophocles' Philoctetes presents the paradigm case. According to White, by showing us in dramatic form the opposition between dolos (trickery) and peitho (sincere persuasion), by moving us from Odysseus' deceit and Neoptolemus' similarly manipulative designs to the latter's "conversion" to sincere and honest persuasion, Sophocles teaches us how to speak to others, and therefore how to be among them.

Thus, White not only tells us how to read in general (as "ideal readers"), ${ }^{141}$ but he also takes us into a particular narrative universe by virtue of his particular reading of Sophocles' moral drama. White takes us in 142 "almost" unawares. After all, White does explain what reading and persuasive rhetoric are and what they do. So we know what he is up to when he leads us through Sophocles' drama. But there remains a significant gap here. How can we be sure White's reading (or anyone else's for that matter) is correct? White discounts this fear. He is confident that "the only imaginable rhetoric" is "sincere and authentic" rhetoric, peitho rather than dolos. ${ }^{143}$ Similarly, the "only imaginable" attitude to take towards persuasion and community from reading Sophocles' drama is that of "recognition and in-

140. Id. at 42-43.

141. White uses "friendship" as a metaphor for the experience of reading:

It is in this process of learning and changing that much of the meaning of a text or of a friendship resides; the text is in fact partly about the ways in which its reader will change in reading it.

....

... [T] he central achievement of a great text can be said to be the ideal reader it defines - the version of oneself it calls into existence and addresses.

Id. at 91-92.

142. See supra note 88 on the overdetermined meaning of "being taken."

143. J.B. White, HERACLES' Bow, supra note 5, at 25. 
tegration." 144 And integration, he adds in an equally confident voice, is the "central value" of the play. ${ }^{145}$

What are we to make of such confidence? Is it justified? My response is that there is much to be made of White's confidence, and that it is not in fact justified. These two observations are related. And I believe they go to the heart of the rhetorical enterprise White is pursuing. White pays a price for placing image and metaphor at the core of our discourse about law. By standing for something, metaphor not only opens up our perception - imagining "this" as "that"146 - it also serves to disguise or mask. For we know that "this" is only like "that"; the image, the signifier, cannot achieve identity with the object, the signified. ${ }^{147}$ The image that persuades us not only "takes us" by presenting us with propositional information; it also "takes us in." 148 And by moving us, it also simultaneously diverts us from our own thoughts, feelings, beliefs. ${ }^{149}$

At stake here is the issue of power or coercion, through deceitful manipulation or plot, versus legitimate authority, through open and sincere persuasion. ${ }^{150}$ White addresses this same issue in his discussion of two different types of discourse, namely dolos and peitho. Now,
144. Id.
145. Id. at 21.
146. See P. Ricoeur, supra note 20, at 252:
Metaphor has been compared to a filter, a screen, and a lens, in order to say that it places things under a perspective and instructs us to "see as ...." Yet, it is also a mask that disguises. It was said that metaphor integrates diversity; but it also leads to categorial con- fusion. It was said that it "stands for . .."; it must be said as well that it is "taken for."

147. Id. at 216-56.

148. That is to say, speech, and in particular the language of the law, not only does something (e.g., creates a contract, say, or decides a specific legal controversy), but it also seeks to achieve certain effects upon others (e.g., the arbitrator's or judge's effort to persuade the parties involved, or the court's effort to frighten the criminal defendant, along with others who might be contemplating the commission of similar acts, in order to deter them). See J. SEARLE, THE Philosophy of LANGUage 7-8 (1971) (noting Austin's distinction between illocutionary speech acts (i.e., speech that does something) and perlocutionary speech acts (i.e., speech that achieves effects upon the other). Cf. P. LAfN ENTRalgo, THE Therapy of THE WORD IN Classical ANTIQUITY 92 (1970) (noting that Plato once called rhetoric psychagogia, or "the art of directing minds by means of speech").

149. See P. Brooks, supra note 16 , at 86 ("To read a novel - and to write one - means to be caught up in the seductive coils of a deviance: to seduce, of course, is to lead from the straight path, to create deviance and transgression.").

As Pucci shows in his analysis of Hesiod, P. PuccI, supra note 107, persuasive rhetoric may aspire to truth (logos as aletheia) but it can never escape the force of eris (falsity: the mythos of lethe); see also M. DETIENNE \& J. VERNANT, supra note 118, at 16, 18, 27-29, 33, 35, 44, 61, 64, 93 (evidencing the close ties that exist between dolos (deception) and metis (cunning)); id. at 8889 (distinguishing "positive" dolos (self-disciplined and prudent cunning in the service of liberation) from "negative" dolos (immoderate or uncontrolled and malevolent trickery that constrains by treachery and violence)).

Cf. Seery, Politics as Ironic Community: On the Themes of Descent and Return in Plato's Republic 16 POLITICAL THEORY 229, 238 (describing the use of irony as an edifying ruse).

150. In other words, where does persuasion end and discursive tyranny begin? Pertinent 
however, the level on which the discussion proceeds will shift from a particular text, be it Sophocles' or White's own, to the nature of discourse or storytelling in general. This theme of power versus authority pervades both Sophocles' and White's texts, particularly at the subtextual level. It is part of the particular unspoken plot which (in different ways and to different ends) unifies and empowers Sophocles' and White's respective authorial voices. Contrary to White's confidence in his interpretation of Sophocles' drama, we may well come to wonder whether persuasive narrative ever persuades without its own hidden, coercive plot. Only by addressing this tension head on can we restore our equanimity and autonomy in the face of the unspoken maneuvers by which the other's discourse - including White's - takes us in. By critical reflection we may seek to reduce the gap between unwitting submission to the other, on the one hand, and knowing and intentional acceptance of authority, on the other.

Before commenting further upon the inextricability of dolos and peitho, unreflected in White's dichotomization of the two, I shall first attempt to show how White's reading of Sophocles' text is not only one among other possible readings, but also a reading that reflects White's own hidden designs. As a result, crucial Sophoclean themes go unnoticed, themes which might well explode the very interpretation that White recommends. For if dolos is inextricably tied to peitho, how can a sincere persuasion ever come of a shrewd emplotment? How can community based on sincerity and friendship ever be realized? But perhaps Sophocles never meant to suggest that either sincere persuasion or the community it gives rise to could be fully realized. Indeed, I believe that upon returning to the text of the Philoctetes we will find that the community Sophocles depicts is far more complex and riven by paradox than the community White discusses.

If White's reading is accepted, Sophocles is telling us that the naked, coercive power of human dolos cannot establish community among mortals. Moreover, peitho can establish community. But what if a different reading prevailed? What if the meaning Sophocles meant to convey is that there are forces of Necessity against which even the most sincere and well-meaning of human designs are like leaves blown by unpredictable, seemingly capricious, winds? ${ }^{151}$ If this is so, perhaps

here is the issue of obedience to, versus acceptance of, legal rules. See Sherwin, supra note 43, at 406 n.83.

151. See Poe, Heroism and Divine Justice in Sophocles' Philoctetes, in 34 MNEMosyne BiBlotheca Classica Batava 1, 34 (1974) (noting that force, rather than guile, is used to a surprising degree in the Philoctetes). Poe also points out that the insufficiency of human understanding has been identified by Hans Diller as a theme running through all of Sophoclean drama. Id. at 38 (citing H. Diller, Göttliches und menschliches Wissen bei Sophokles, in GoTTHEIT 
human designs must submit to those of a higher order. Indeed, the virtue of piety consists in mortals doing precisely this. In this view, then, piety, rather than peitho, may be taken as the supreme value in Sophocles' narrative nomos. In my view, this is a reading which Sophocles' Philoctetes invites. ${ }^{152}$ It depicts a theme which obsessed this great playwright throughout his long lifetime: namely, the mythos of fate overpowering human will. 153

According to this reading, Sophocles' Philoctetes is suffused with the theme of power (both mortal and Divine) versus authority (also both mortal and Divine). By a series of paradoxical pairings, Sophocles subjects each of his characters to strange inversions. In the process, he not only casts doubt on the ability of mortals to persuade one another but also raises a specter of futility over efforts to try. Perhaps the crowning irony is that in the end even Sophocles' own proffered resolution of this dilemma becomes suspect.

Sophocles' drama unfolds against the backdrop of a prophecy. When brought before the Greeks, Helenus, a Trojan captured singlehandedly by Odysseus, prophesies that Troy will never be defeated unless Philoctetes returns with his god-given bow. Only then, he says, will Philoctetes be cured of his god-sent injury, and will both he and Neoptolemus gain glory in battle against the Trojans.

What ensues in Sophocles' story is a series of paradoxical juxtapositions:

1(a) Opposing fate, Philoctetes claims righteous indignation and justice: he will not return to help those who betrayed him, leaving him to suffer alone in exile.

1(b) Embracing fate, Odysseus claims the ends justify the means: the deception of Philoctetes serves a higher cause, one that "is destined."

Yet, neither Philoctetes nor Odysseus succeeds on his own terms. Odysseus' strategy only temporarily takes Neoptolemus in, and Neoptolemus' deception of Philoctetes is similarly short-lived. On the other hand, Philoctetes' sense of justice is ultimately defeated by the intervention of Heracles, who bespeaks Divine Justice or Necessity.

UND MeNSCh IN DER TRagödie des Sophokles 1 (1963)). For his own part, Poe observes that in the Philoctetes control "is almost completely out of the hands of mortals. The gods initiate the action and in the end bring it to accomplishment." Id. at 38.

152. But cf. P. LAín EnTralgo, supra note 148, at 64-68.

153. See also C. Thirlwall, Remains LtTerary and Theological 9-10 (1878):

Not even the most superficial reader of [Sophocles'] works can fail to observe that they are all impressed with a deep religious character, that he takes every opportunity of directing the attention of his audience to an over-ruling Power, and appears to consider his own most important function to be that of interpreting its decrees. 
2(a) Opposing fate, Philoctetes succeeds in sincerely persuading Neoptolemus to act as a friend, and to do what Neoptolemus had falsely promised before: namely, to end Philoctetes' lonely exile and return him to his homeland.

2(b) Embracing fate, claiming that Necessity compels it, Neoptolemus nevertheless fails to persuade Philoctetes as a friend to do what is in Philoctetes' best interest: namely, to return with the Achaeans and find health and glory.

Yet, both Philoctetes' "success" and Neoptolemus' "failure" are temporary only; Neoptolemus' failed attempt at sincere persuasion is ultimately reversed, albeit by divine intervention; conversely, the same intervention turns Philoctetes' success into failure: he must join the Achaeans after all, notwithstanding the injustices he suffered.

3(a) Opposing sincere, honest persuasion, both Odysseus and Philoctetes succeed in their manipulative strategies. Odysseus converts Neoptolemus to the former's instrumental designs; for his part, Neoptolemus successfully takes in Philoctetes, winning the latter's bow by deceit.

3(b) Embracing sincere, honest persuasion, Neoptolemus still fails initially to persuade Odysseus that honesty with Philoctetes is a better method than deception; and he fails again later on in his sincere efforts to win over Philoctetes.

Yet, both the victory of dolos (by Odysseus over Neoptolemus and by the latter over Philoctetes) and the defeat of peitho are overturned in the end - by divine compulsion.

4(a) Intending deception, Neoptolemus actually tells Philoctetes the truth: Neoptolemus describes himself to Philoctetes as a victim of Odysseus' deceit only to discover later that he was in fact, as was Philoctetes, a mere agent of Odysseus' instrumental designs.

4(b) Intending truth and justice, Philoctetes disparages the gods and professes his inability to show them proper piety. In response to Neoptolemus' false tale of abuse at Odysseus' hands, Philoctetes bemoans his tragic fate and the heartlessness of the gods who suffer villains like Odysseus to succeed in worldly affairs, while righteous mortals like Philoctetes (and, he naïvely believes, like Neoptolemus) are left innocently to suffer injustice. Reasoning this way, Philoctetes defies Helenus' prophecy.

Yet, both Neoptolemus and Philoctetes are converted to opposing positions. Neoptolemus realizes that he has been deceitfully manipulated and that he must throw off Odysseus' methods; Philoctetes comes to realize that, contrary to his earlier impious remarks, the will 
of the gods cannot be resisted, and that his pathological clinging to his injury reflects a false self-righteousness.

5(a) Commanding compliance, Heracles induces Philoctetes to accept his fate, to be healed and serve as Troy's conqueror alongside Neoptolemus, as was prophesied.

5(b) Inducing belief with manipulative plot, Sophocles moves us to accept divine Necessity as comporting with divine Justice.

Yet, both Heracles and the playwright subvert individual autonomy and freedom of choice. Heracles mocks human will by replacing unsuccessful, sincere mortal persuasion with divine coercion. In the name of celebrating freedom, Sophocles relies on theatrical manipulation; he resorts to deus ex machina to overcome the tensions created by his characters' human error and stubbornness.

In this sense, the paradoxical counterpart to the divine coercion which Sophocles interposes as "necessity," and perhaps "justice" as well, is a narrative device. After all, it is the force of Sophocles' (mortal/coercive) plot by which mortal designs are shown to be futile in the face of divine intervention. But can mortal designs be made to turn upon themselves in this way? Can one subvert the power of human design without also inducing mistrust in the very language that seeks to carry out such a task?

According to this reading of Sophocles' Philoctetes, piety - mortal submission to divine will - becomes the paramount theme. ${ }^{154}$ Thus,

154. Some critics have in fact read the Philoctetes as a testament to Sophocles' skepticism about the existence of the gods. For example, according to Poe, the gods' "achievement by fiat of their desires makes the struggles which have taken place on the stage, and over which the audience has agonized, completely inconsequential." Poe, supra note 151, at 10 . Poe describes this breakdown of dramatic cause and effect (Sophocles" "deliberate" use of the nonsequitur, ["the calculated absence of causal relationship between events"]) as reminiscent of the primary device of the modern theatre of the absurd. Id.

Thus, for Poe, Sophocles' drama carries an existential message. Praising Philoctetes for his unwavering "moral firmness," even in the face of utmost degradation at the hands of scheming men and indifferent gods, Poe concludes: "If there is no cosmic justice at least there is hope in man, who can defend his own values." Id. at 50.

Whether this is what Sophocles intended to convey or is simply Poe's projection of midtwentieth-century existential philosophy remains problematic. It warrants noting, however, that Philoctetes' willingness to renounce even his treasured righteousness when directly faced with the god's decree, and in this way perhaps also indicating his willingness to accept his suffering and all that led to it, may suggest more than "moral firmness." Not unlike the story that the Book of Job tells, it may suggest that it is the sovereign power of the god alone to which Philoctetes must yield. Viewed in this light, Philoctetes' wound - perhaps symbolizing mortal injustice - is not inconsistent with immortal justice. Indeed, one may say that it is only through suffering the wound of mortal justice that we come to view a higher justice. Mortal suffering lacks reasons. Yet, it is precisely this limitation of reason that reveals the lacuna between the human world and the divine. To bridge that distance, one must accept the wound together with the inarticulable suffering and lonely anguish that it entails. Thus, based on a Jobian reading of the Philoctetes, suffering the wound of mortality knowingly and willingly gives birth to curative belief and affirmation; it signifies the creature's awakening to the transcendental justice of creation itself. Perhaps, then, in this context the claimed right to be persuaded is but another gesture of 
while we may agree with White that sincere persuasion provides the most acceptable basis upon which to establish human community, its efficacy has now become problematic. For we have seen in the Philoctetes that human designs seem to fail when they are good and to succeed when they are bad. ${ }^{155}$ And while mortal coercion may sometimes succeed when it should not, or fail when it should succeed, divine or narrative - coercion, Sophocles seems to be telling us, should not be questioned, even when suspicion might tell us otherwise. How can we accept White's claim that the only attitude the play leaves us with favors sincere persuasion in the service of integration when we see such persuasion fail on its own terms or appear impotent in the face of divine coercion? Can we hope to know what "justice" is when what seems unfair turns out to be divinely willed? After all, Philoctetes' innocent suffering seems a just reason for him to refuse his aid to his countrymen. Yet, Heracles forces him to assist his betrayers. How can we condemn coercion when it alone, in the form either of Sophocles' plot or of Heracles' command, provides the route to Philoctetes' cure?

How can we agree with White that Sophocles' play projects an egalitarian community based on sincere persuasion and integration when in fact it champions the coercive force of divine command leaving us to doubt the efficacy of anything but divine will? In lieu of White's notion of "integration," why aren't piety and fatalism the core values of the play? Instead of the development of a particular character, another of White's themes, isn't the impersonal play of cosmic necessity at the drama's center?

Finally, even if the foregoing interpretation is faulty, and White's is to be preferred, why should we adopt the Philoctetes as the paradigm text for how constitutive rhetoric operates? Even if we were to assent to its use, can we not question how much of ourselves and our commu-

hubris. Are "reasons" appropriate here? Or, is absurdity (of divine intervention/command) a credo in its own right? Compare Tertullian's credo quia absurdum ("I believe by virtue of the absurd") (cited in S. KIERKEGAARD, THE CONCEPT OF IRONY 426 n.14 (1966)).

That acceptance of irrational suffering may be the beginning of wisdom and belief has been suggested before by Sophocles. We find it in his tale of King Oedipus' utter reversal, from admired sovereign to despised pariah. See C. ThIRwall, supra note 153:

Now, as soon as the first paroxysm of grief has subsided, [Oedipus] appears chastened, sobered, humbled: the first and most painful step to true knowledge and inward peace has been taken; and he already feels an assurance that he is henceforward an especial object of divine protection, which will shield him from all ordinary ills and dangers.

Id. at 19. Compare Job's enrichment following his own suffering-induced leap of faith.

155. For example, as we saw above, Philoctetes stubbornly rejects Neoptolemus' sincere appeal; and even when Neoptolemus finally rejects Odysseus' dolos, Philoctetes' willfulness stymies Neoptolemus' peitho. This leaves us to wonder whether Odysseus' original strategy may have been "right" after all. By what right can we condemn Odysseus, whose actions may well have advanced divine will? 
nity we can recognize within its ancient language and traditions? After all, the culture of the Greeks is far removed from ours today. For them piety or love of comradeship and community based upon honesty and friendship may have served as common points of departure, grounded in a cultural consensus, much the way the Greeks shared in common the Homeric and Hesiodic tales of heroes and divinities. But surely contemporary circumstances differ drastically. ${ }^{156}$

Why not, then, choose as paradigmatic a text closer to home? Let's say, for example, Stendahl's The Red and the Black, or Flaubert's Sentimental Education? There at least we recognize the peculiar modern situation by identifying with the author's self-conscious suspicion of narrative design itself. ${ }^{157}$ Consider Stendahl, in whose hands the theme of naked power versus legitimate authority comes to the forefront of narrative design and content alike. In The Red and the Black, the self-conscious narrator's tale turns upon itself, ${ }^{158}$ guillotining its main character along with the plot. ${ }^{159}$ This appears to be a

156. See, e.g., A. MACINTYRe, AFTER VIRTUE 262 (1984) (claiming that all the political traditions within our culture today are exhausted).

157. See P. BRooks, supra note 16, at 37-89; see also Pierssens, What Does Fiction Know?, 17 SUBSTANCE 1, 9-10 (1988) ""The typical form of a modern narrative will be that of the wandering about of characters thrown into a labyrinth but without Ariadne waiting for them outside, for there is no outside, only an unlimited network of possible paths that make it impossible to go back."); N. SARRAUTE, L'ERE DU SOUPCON 59 (1956):

[Cette evolution actuelle du personnage du roman] témoigne, à la fois chez l'auteur et chez le lecteur, d'un état d'esprit singulièrement sohpistiqué. Non seulement ils se méfient du personnage de roman, mais, à travers lui, ils se méfient l'un de l'autre. ... Quand on examine sa situation actuelle, on est tenté de se dire qu'elle illustre à merveille mot de Stendahl: "le génie du soupcôn est venue au monde." Nous sommes entrés dans l'ère du soupçon.

Translation of Sarraute quote: [The present evolution of the character in fiction shows, on the part of both the author and the reader, a singularly sophisticated state of mind. Not only do they mistrust the character, but through him, they mistrust each other. ... When one looks at the present situation, one is tempted to say that it illustrates wonderfully well the words of Stendahl: "the genius of suspicion has come upon the scene." We have entered into the age of suspicion. (Translation provided by John Lazar. - Ed.)].

158. As in more contemporary works, for example, William Faulkner's The Sound and the Fury, John Barth's Chimera, Henry Miller's Tropic of Cancer, and the later postmoderns - such as Robbe-Grillet, Beckett, and Calvino.

159. For example, in Stendahl's The Red and the Black, the author hands his main character over to the guillotine in order to collapse the novel back into a story that Stendahl found in $\mathbf{L a}$ Gazette des Tribunaux, a newspaper article that he used as the outline for his novel, and from which the novel's story had diverged. STENDAHL, THE RED AND tHE BLACK (Modern Library ed. 1926). In other words, the plot collapses when pitted against external reality, as the author self-consciously struggles with his own imaginative reworkings of history in narrative plotting. As Brooks puts it:

This outcome may on the one hand reflect that [the main character's] plot finally is not his own, to shape as he wills. On the other hand, it may suggest a more general suspicion of narrative invention, which appears to be subject to interference from outside texts - to the uncontrollable intrusion of a newspaper fragment, for example, that at the last constitutes a mortal intertext.

P. BRooks, supra note 16 , at 83 (emphasis added). 
theme more in keeping with our own time: witnessing the author's manifest distrust toward his own claim to authority. ${ }^{160}$ Distrust suits an age of self-elusiveness, where unconscious desire lies hidden in every manifest gesture or speech. The supposedly "senseless" slip of the tongue, the fractured dream image, even the painter's abstract field of colorist expression or the discordant tonalities of contemporary composition tell us more about ourselves than we can otherwise say.

But perhaps we have escaped from the Freudian masterplot, grown suspicious of suspicion. I think not, however. And to the extent that this is so, we must continually strive to discover where such suspicions lead us. Yet, if tropos (in narrative form, with its multiple figures and images, and its manifold plots and characterizations) ${ }^{161}$ is to triumph over atropos ${ }^{162}$ (whether in the form of logic, with its rigid and rigorous methods of proof, or in the form of divine necessity, with its equally stringent, but unknowable dictates), does this not signify our embrace of the relativist mindset about which the critics have warned? Can we stem the tide of creative figurative discourse and the multiplicity of meanings that it allows? I contend that we can, and that rhetoric need not breed facile relativism. While it may be true that by making explicit the need to articulate and defend underlying beliefs critical rhetorical practice invites controversy, it certainly does not negate the affirmation of norms. Rather, deliberate normative affirmation and accommodation must come to be seen as the legal system's chief institutional objectives.

Recognizing that rhetoric in the absence of self-reflectively articulable standards or regulative ideals risks collapsing into some form of persuasion for its own sake, the challenge becomes: how can we save the substantial insights White's constitutive rhetoric provides without falling prey to the dolos by which even his text would take us in? For I believe that it is the hidden plot in White's text (whether intentional or unwitting) that has him cast Sophocles' play in terms that are congenial to White's point of view regarding law and the legal culture even if this reading is less congenial to the Sophoclean nomos.

White effectively counters the rigidity and impersonality of abstract and comprehensive conceptual schemas by interposing poetics

160. See P. Laf́ ENTRALGo, supra note 148.

161. Tropos, the plasticity of human figurative expression, signals human freedom from divine or intransigent order or necessity, but risks disorder (or perhaps even anarchy) by virtue of its open invitation to capricious impulses and malevolent desires.

162. See HesIod; Theogony 95, 239 (H.G. Evelyn-White trans. 1977) (describing Atropos as the eldest and chief of the three fates - who cuts the thread of necessity: "She who cannot be turned is the 'Fury with the abhorred shears' "). 
and rhetoric as alternative ways of thinking and speaking about law, legal practice and legal education. But he fails to recognize the particular circumstances in which different voices may appropriately come into play - or, upon critical self-reflection, be appropriately excluded. ${ }^{163}$ In short, White's analysis leaves unclear the role particular voices may be best suited to play within the decisionmaking process. ${ }^{164}$ These omissions, which are due at least in part to an inadequately articulated normative framework, leave the dangers of communicative distortion and dominance unrecognized and unchecked. ${ }^{165}$

The omission in White's reading of Sophocles' play of any reference to the power/authority controversy is both symptomatic and paradigmatic. It is symptomatic because it reveals White's openness to congenial readings and his resistance to alternative readings which put in jeopardy the rhetorical nomos he would like to see established in contemporary legal culture. His reading betrays an underlying plot: the inauguration of "constitutive rhetoric," and the diminishment of a cultural commitment to bureaucratic cost/benefit analysis, the "instrumental language of systems design."166 It is paradigmatic in the sense that every interpretive judgment engages narrative emplotment, a kind of authorial symptomatology of conscious or unconscious preferences and resistances. I alluded to this phenomenon earlier when I suggested that the relationship between peitho and dolos is not dichotomous, as White suggests, but rather interpenetrating. Yet, if the relationship between peitho and dolos is as I have suggested, what then is the nature of their interpenetration in a given interpretive judgment, and by what critical standards do we assess the worth of that

163. See Sherwin, supra note 4 (describing an intra-judicial institution of checks and balances among discrete forms of legal discourse as a source of normative guidelines for legitimate decisionmaking, citing the Miranda doctrine in confessions law as illustrative of incommensurability but not the incompatibility of different legal dialects).

164. See id. See also supra Part I (discussion regarding choosing authoritative types of discourse).

The essence of the type of dialogical dominance at work here is superbly captured in one of Pascal's pensées: "Tyranny is the wish to obtain by one means [read discourse] what can only be had by another. We owe different duties to different qualities: love is the proper response to charm, fear to strength, and belief to learning." M. WALzER, SPHERES OF JUSTICE 18 (1983) (quoting Pascal). Thus, responding to charm with belief or to strength with love is in a sense tragic, and perhaps even perverse. Compare Marx's comment: "If you love without evoking love in return, i.e., if you are not able, by the manifestation of yourself as a loving person, to make yourself a beloved person - then your love is impotent and a misfortune." Id. (quoting Marx).

165. For example, distortion can occur overtly by a show of naked strength (e.g., Odysseus reaching for his sword). It can also occur, perhaps even more menacingly and pervasively, covertly by intentional deceptions or plots (e.g., Neoptolemus' witting design upon Philoctetes, or Sophocles' or White's narrative designs upon their readers). Another form of covert distortion arises from an author's unwitting partialities (e.g., White's lauding of common-sense blaming).

166. J.B. WHITE, HERACLES'Bow, supra note 5, at 195. 
judgment? ${ }^{167}$

To begin an adequate response to this question, we must first rid ourselves of the false dichotomy that White posits. Given that there is no way fully to extricate persuasion from emplotment of one kind or another, the best course is constantly to strive to recognize and appreciate the changing relationships between these two forces within particular contexts. We must remain aware of the ever-present dialectic between "ideal reading" and suspicion.

In what follows, I shall apply this dialectical analysis to a particular regulative theory and a specific normative institutional structure. To achieve legitimate interactive discourse within the legal culture, we must recognize the rhetorical truth that particular audiences obtain privileged authority under different circumstances. At the same time, we must specify the conditions of limitation and entitlement that will legitimize this practice. By deliberately instituting checks and balances among the discrete dialects of the law, we can provide appropriate constraints upon controllers of legal discourse. In this way, suspicion - and the critical interpretive practice that it makes possible - emerges as a necessary safeguard against the risk of rhetorical domination. Only with awareness of the plot that would take us in, of the textual or personal prejudices, of the hidden or conflicting regulative concepts or normative ideals that shape and inform narrative, can we deliberately articulate reasons explaining and justifying specific normative endorsements. ${ }^{168}$

\section{The Dialectic OF INTERPRETIVE JUdGMENT}

In this final part, I recast the discussion in explicitly normative terms. I examine the different ways in which value endorsements are made, depending upon the type of discourse we choose to authorize (i.e., by making it an official language of power in society).

167. Or, putting the matter differently, given the ineluctable interpenetration of dolos and peitho, how can we maximize the latter and minimize the former by bringing to the surface good reasons for accepting a particular judgment?

168. The idea here is that knowledge of discursive plotting can help us to counter the coercive features inherent in any rhetorical practice. See P. CoRBETT, supra note 26, at 66 ("The point is merely that we must get into the way of asking, as a standard precaution, how the persuasive forces of words are being used in each particular case.").

The term "knowledge" as used above is meant in a Freudian sense. That is, by allowing particular, previously hidden themes to enter consciousness, we are empowered to take responsibility for, knowingly and intelligently to decide, whether or not our subsequent actions will continue to be guided and informed by them. Transposed into a legal context, this means that selfreflective explanation and justification for particular interpretive judgments are necessary to make acceptable, and therefore to legitimize, particular rhetorical emplotments. Rhetorical persuasion thus emerges amidst controversy as reasoned debate rather than as pure instrumental efficacy. 
According to White, the way in which we choose to speak and think about self, others, and social institutions helps to constitute our personal and social reality ${ }^{169}$ (what Cover idiosyncratically calls nomos). ${ }^{170}$ In the current legal culture, White says, a particular authorized way of thinking and speaking has achieved great influence among judges, lawyers, and legal scholars. White refers to this form of discourse as instrumental systems design talk. ${ }^{171}$ He fears that this type of rhetoric has the effect of devaluing the individual, of reducing her integrity, autonomy, and freedom to speak and act among others as an equal. It does this by superimposing upon the individual a bureaucratic, highly centralized discursive system for resolving disputes. This system slots the individual into its own structure and treats her accordingly.

Instrumental systems design talk is committed at the outset to particular social purposes or interests. For instance, in the criminal law those who speak in this dialect may opt for deterrence, or incapacitation, or rehabilitation, or retribution as the preferred interest or purpose which the legal system should pursue. ${ }^{172}$ Each of these discrete purposes or goals not only serves as a putative basis for legitimizing the criminal law but also generates its own unique way of characterizing the criminal defendant, the police, and the victim of crime. Moreover, each proffered goal has its own preferred way of emplotting the dramas in which these people are involved; selecting a goal gives a particular structure and coherence to the legal stories told by those involved. As White puts it: "The idea is that once these purposes have been agreed upon, they can form a basis upon which the institutions of the criminal law can be shaped and action within it guided and controlled."173 White adds that cost-benefit analysis typically operates in tandem with instrumental policymaking. ${ }^{174}$

Problematically, each preferred policy commitment, each discrete interest or purposive ideal, operates in a way that is both totalizing and exclusive. Centering policy around retribution, say, or rehabilitation, tends to generate a particular, internally consistent system. And since the purposes referred to above are conflicting, if not mutually exclusive, the system each gives rise to is similarly cut off from one another. This totalization of partial and exclusive perspectives dimin-

169. See, e.g., J.B. WhITE, HeRACLES' Bow, supra note 5, at 28-48.

170. See Cover, supra note 36.

171. See J.B. White, Heracles' Bow, supra note 5, at 195.

172. Id. at 194-95.

173. $I d$.

174. Id. 
ishes those whom the system incorporates into its own terms. There seems to be no way to integrate the disparate visions or characterizations of self, other, and social reality that each comprehensive system spawns.

To offset the splintering and totalizing effects of instrumental system designs talk, White interposes the type of constitutive rhetoric which he claims to have derived from Sophocles' Philoctetes. In a community that is based upon sincere persuasion rather than manipulation, White says, the individual (accused, victim, police, prosecutor, judge) would not be reduced to the artificially simplified and distorting terms of a particular, subjectively preferred abstract and comprehensive system. ${ }^{175}$ Instead, White suggests, common-sense blaming holding the other accountable as a function of ordinary language rather than artificial and esoteric social policy talk - would prevail. 176 Presumably, then, the analogy that extends from the Philoctetes is this: people in the criminal justice system whose responsibility it is to examine the accountability of others must perform their task more like the enlightened, sincere Neoptolemus, than like the deceitful and manipulative Odysseus. Rather than fit the accused into a system of ends which are antecedently defined and which cannot be questioned thereafter (recall Odysseus' vow that Philoctetes and his bow must be taken - one way or another), the accused must be judged as a full person, in a specific context, as a member of the community who has his own needs and desires, as someone with a personal history, as one who ultimately must be integrated back into the same community that might choose to exile him for his wrongdoing. Viewed in this manner, the criminal process affords both the accused and the victim an equal opportunity to tell his or her own story. 177 And since judgment proceeds according to the lights of ordinary blaming, it operates within the province of the lay jurist, rather than that of the legal specialist.

There is merit to White's proposal that the rhetoric of blaming should take the place of systems design talk as a basis for making sense of the criminal process. But upon further reflection, serious difficulties emerge. Not surprisingly perhaps, they are the same difficulties which confront us whenever we privilege a particular form of discourse over another. For we encounter the dangers of distortion when we privilege the discourse of common sense and the rhetorical community of the lay public over utilitarian systems design talk and the community

175. Id. at 198-99.

176. Id. at 200-01.

177. Id. at 200-01, 211. 
of expert social policymakers - just as we encounter them when the dominance runs the other way. Certainly systems design talk may artificially reduce individuals to make them comport with narrow, antecedently defined characterizations of self or social reality, but common sense is no less susceptible to partialities of its own. ${ }^{178}$

For example, can common-sense blaming coexist with those often counter-intuitive notions of justice which set the factually guilty criminal defendant free? ${ }^{179}$ Can common sense make sense of interpretive principles, deriving, say, from a constitutional text, which trump our "natural" inclination to blame the factually guilty?180 Common sense probably would not surrender concrete evidentiary truth to abstract constitutional principle - whether that principle be a matter of construing fourteenth amendment due process or the fifth amendment privilege against self-incrimination. ${ }^{181}$ This sort of textual choice and subsequent interpretation appear to lie within the domain of experts after all. Indeed, this specialized interpretive function may well serve as a vital check upon conventional majoritarian prejudices which could easily place the unpopular, socially marginal figure of the criminal accused at risk of receiving less than equal protection and due process of law.

In other words, particular forms of discourse manifest biases of one kind or another. To the extent that each dialogic perspective embodies discrete conceptual prejudices which inform and shape particular characterizations of self, other, and social reality, there is always a danger in isolating one type of discourse (and, correlatively, one aspect of self or social reality). Notwithstanding the virtues of each type of discourse, further reflection will show that each also has its own distinct defects and limitations. Indeed, the significance of the latter increases when one elevates a particular type of discourse and its corresponding dialogic community to the status of a preferred (or dominant) language of power in society. For this move simultaneously disempowers (by shrouding in silence) those who would speak in a different voice. In the process of authorizing a particular form of discourse, by privileging it over others, one totalizes its partialities, thus leaving its defects to run wild - ultimately allowing them to

178. See B. Whorf, Language, Thought, and Reality 247 (1956); P. Berger \& T. LUCKMANN, supra note 51, at 21.

179. Cf. Judge Cardozo's opinion in People v. Defore, 242 N.Y. 13, 21 (1926) ("The criminal is to go free because the constable has blundered.").

180. See, e.g., Miranda v. Arizona, 384 U.S. 436 (1966).

181. See, e.g., Brown v. Mississippi, 297 U.S. 278 (1936). 
swallow up whatever virtues that form of discourse might have initially possessed.

In sum, White seeks to redress what he perceives as a discursive imbalance within the current legal culture. By privileging instrumental utilitarian talk above other modes of discourse, modern-day jurists are in danger of constituting a social community that fails to do justice to the full range and worth of its individual members. But by failing to address the dangers of ordinary language, by omitting from his discussion the distortions (the hidden prejudices, the unwitting deceits, the masked impulses) and the ill-articulated normative ideals which even constitutive rhetoric is prey to, White leaves intact a different but no less formidable risk of domination. For whether explicitly defined as a comprehensive policy, or left as a hidden, but totalizing bias, yielding to the power of a single discourse imperils the equality and integrity of some at the hands of those who wield the privileged discourse.

I have suggested that coercion by narrative emplotment works by "taking us in." In this sense, the persuasive image, the potent metaphor by which rhetoric traditionally operates, has a coercive dimension not unlike that of the imageless concept's rigid and demanding regulative ideal. The difference between them may lie, at least in part, in the source and context of the authority they lay claim to. As we have seen, for the advocate of the systems design approach, authority consists in a regulative ideal or foundational value that can be defined at the outset of discourse and that serves as the touchstone for all subsequent narrative emplotments. For the advocate of constitutive rhetoric, however, rather than existing before the text, the determinative authority tends to lie within it. That is, instead of occurring prior to encountering the text presented by the other, meaning is here understood as emerging out of the reader/listener's direct encounter with that text. ${ }^{182}$

For the constitutive rhetorician, then, meaning exists as a possibility embodied within the text. It is the text itself that holds the power to open up a world - a mythos or a nomos. ${ }^{183}$ But as critical reflection has shown, since it is the act of reading that gives the possibility of meaning concrete embodiment, being taken in by the text poses two dangers. One is that the reader might experience a conversion to the putative "truth" of the text without fully appreciating what is going on. It is here that the covert deceptions of image and plot come into

182. Cf. P. Ricoeur, Hermeneutics AND the Human Sciences 141-44 (1981).

183. Id. at 93. 
play. Consider, for example, the omissions in White's reading of Sophocles, possibly reflecting White's own interests or resistances to alternative interpretive possibilities. The second danger posed by being taken in by the text is manifest in the subjective distortions that come not from the author but from the reader herself. The meanings that "make sense" to us (and those that fail to) may be the product of our own prejudices, our own personal interests, inclinations, needs, fears, resistances. How do we free ourselves from the "false consciousness" of self, much less that of the other?

If ideal reading introduces me to imaginative variations of self and social reality, it is suspicion that allows me to reflect critically upon the merits or demerits of the text that seeks to appropriate my sense of self and community. Similarly, in order fully to appreciate what the text offers, I must step back and critically reflect upon my own sense of self and community. For upon reflection I find that my subjective understanding of self, other and social reality - for example, my expectations regarding how people ordinarily behave and my sense of how social institutions function - is made up of prejudices which guide and inform my understanding. It is only natural, indeed inescapable, that people living in a particular time and place, with a particular history, culture and character, inherit particular prejudices. There is no "neutral context" outside of a given time and place where "objective" understandings operate - not in the domain of science, and not in the domain of everyday life. It is by virtue of our prejudices that we make sense (or distort or blot out the sense) of the others and texts that we encounter. ${ }^{184}$ However, whether we self-reflectively and knowingly choose to think, speak, or act on the basis of one particular prejudice or another is a different matter. Indeed, by knowledge and intentionality we enable ourselves to take responsibility for our choices. ${ }^{185}$

If the deceptions or false consciousness that lies within our reading and understanding of the text is to be self-reflectively checked, if not altogether vanquished, critical distancing from self and from the prejudices of the text must become an essential part of the interpretive, judgmental process. In other.words, the ideal reading that White describes must find its complement in the reality testing of critical reflection. By this critical process we arrive at the reasons that explain and justify one understanding or interpretive judgment as opposed to another. And it is here that the need for critical theory asserts itself most strongly. Because dissimulation is a common counterpart to the exer-

184. See, e.g., H. GAdAMER, Truth AND Method, supra note 13, at 235-74.

185. Id. at 238 . 
cise of power, knowledge may be viewed as a basis for reversing and perhaps even disposing of the coercive distortions to which domination subjects us. As Taylor has stated: "[T] (domination) makes essential use of the negation of the other (disguise)."186

To achieve this requires us to articulate self-reflectively, to explain carefully and justify, those normative commitments which we discover within the text and within ourselves. Exercising suspicion, we can uncover the hidden plots and designs that give coherence to discourse. Consequently, those plots and designs may be subjected to deliberate normative scrutiny. Turning critical self-reflection ${ }^{187}$ upon persuasive images and characterizations allows us knowingly and intelligently to endorse or reject them and their correlative visions of social reality. We can neither presume prior external consensus upon a particular privileged foundational ideal nor immediate internal accord between our own normative convictions and those of the other as embodied in the text. Instead, the task that critical interpretation requires is unceasingly to question the possibilities the text opens before us in the light of particular regulative concepts or metaphors. So long as we remain sensitive to the shadow of distortion and domination, the critical responsibility to articulate candidly and defend (or reject) operative legal norms may be met. ${ }^{188}$,

Caught between the compelling images and regulative ideals which hope and passion portray on the one hand, and the more sober recognition of alienation, domination, and distortion in human communication on the other, the reality of human finitude weighs heavily upon us. Yet this is the burden that comes of our responsibility as discur-

186. Taylor, Foucault on Freedom and Truth, 12 Political TheoRy 152, 152 (1984).

Habermas suggests that critical reflection has an emancipatory power, that it can free us from such distortions as false consciousness and alienation. See, e.g., J. HABERMAS, CommUNiCATION AND THE EVOLUTION OF SOCIETY, supra note 28. Adopting Gadamer's more cautionary approach, however, one may argue that Habermas' claim is exaggerated, if not flat out utopian in nature. See H. Gadamer, Philosophical Hermeneutics, supra note 13, at 26-38.

Not unlike the philosophy of the Enlightenment, Habermas' defiance of history seems to reflect the search for a theoretical "meta-context" within which universal norms measure our judgments and actions. In contrast to this view, Gadamer has made clear that there is no such thing as complete emancipation from normative or cultural partiality. No one can step wholly outside of his or her own cultural or characterological or historical milieu. The very language we speak, the questions or dilemmas we take as our own, and the values at our disposal to assess them, are largely inherited. See H. GADAMER, supra. Thus prejudice (our linguistic heritage) acts as an ineluctably constraining force upon our freedom to identify and choose the good or the right or the healthful.

187. What Ricoeur refers to as the critical moment of distanciation from metaphorical or poetic utterance. See P. RicoeuR, supra note 20, at 313 .

188. See P. Ricoeur, supra note 182 , at 93. 
sive co-creators of self and social reality. ${ }^{189}$ With knowledge of this freedom and its accompanying responsibility in mind, it is incumbent upon us to recognize the consequences that flow from thinking and speaking in one way as opposed to another. This means that we must also come to recognize the singular virtues and defects which particular types of discourse enjoy. 'For only then can we freely and knowingly choose how best to speak among (and about) others in society. Only then, moreover, can we assess power relationships that may exist among, and that can be established by, discrete modes of rhetorical expression.

This then is the theory that I submit. It poses as a foundation for our democratic institutions - as a collective, consensual point of departure - the need to guarantee the opportunity of every individual to speak and be heard when she claims a violation of her rights or interests. As Ackerman poignantly puts it, we may recognize the paradigmatic ground of political right by "its insistence that all people submit to questioning about the things they hold dearest; that all of us contemplate the possibility that our moral vision may be distorted; that all of us accept the discipline of dialogue and restrain the temptation to destroy those whom we cannot convince."190 Absent adequate recognition of the consequences of authorizing one legal discourse rather than another to settle particular disputes, and without a system of checks and balances among discrete discourses of power to protect against dialogic dominance, the danger of tyranny persists.

In this view, democratic discourse is incompatible with the privileging of some forms of discourse at the expense of silencing others. ${ }^{191}$ If inequality mocks discourse, democratic institutions must seek the reverse: they must strive to open multiple lines of communication, to institutionalize discursive reciprocity, using our collective discourse to overcome individual inequality. ${ }^{192}$ In Booth's words:

189. See P. CoRbeTt, supra note 26, at 192 ("We must now conceive our schemes and images as schemes and images: not as exclusive apprehensions of objective truth, but as instruments of human self-creation."). Cf. D. VERENE, supra note 68 , at 165 :

The forms generated by our powers of memory and imagination orient toward oppositions and make possible human choice. Oppositions are dealt with in a determinate fashion only in such acts of choice. ... Understood in this sense rhetoric is an activity in which the mind constructs a knowledge of itself. As this master form of thought, narration is always as much about the subject to which its attention is directed as it is about its own nature.

See also R. RORTY, supra note 30.

190. B. ACKERMAN, supra note 2, at 348.

191. See Rawls, supra note 52; see also Cornell, Post-Structuralism, The Ethicall Relation and the Law, 9 CARDozo L. REV. 1587, 1625 (1988) ("[O]nly a self that constantly seeks to divest itself of sovereign subjectivity will be upen to relations of reciprocity."). Cornell goes on to note that the decentered subject is "the very condition of relations of reciprocity." Id.

192. See generally Sherwin, supra note 4. 
"Whenever any person or institution violates the inherent values of free human exchange among persons, imposing upon anyone a diminution of his nature as a rhetorical animal, he is now shown to be ... wrong." 193 And because it is persuasive reasons, and not merely "selfevident" or purely intuitive convictions ${ }^{194}$ upon which the legitimation of authorized discourse depends, the debate this theory opens up must be explicitly normative. ${ }^{195}$

In the space that remains, I would like to articulate in more concrete form some of the ideas expressed above. I will be relying upon a theoretical "masterplot" that views the language of democracy as, on the one hand, a means of maximizing the opportunity for individuals to participate in collective discourse and, on the other, of minimizing the tyranny imposed by a dominant, officially empowered form of discourse. I seek to show how a particular institutional or structural principle specifically emplots particular forms of discourse within a specific context. The principle I have in mind extends the well-known idea of checks and balances among the three branches of government from being an institutional antidote to political tyranny to being an antidote to political tyranny within the judiciary branch itself. More specifically, I would like to consider the process of checks and balances as an intra-judicial institution among the discrete types of discourse by which lawyers and judges tell stories and make judgments about particular legal controversies. ${ }^{196}$ According to this approach, it is essential that legal practitioners, decisionmakers, and scholars recognize the unique competencies of particular forms of legal discourse.

The particular controversy I shall focus upon is already familiar to us. It is the one Sophocles describes in the Philoctetes. So far we have encountered two alternative ways of reading the Philoctetes. According to White's reading, the play provides us with a regulative ideal based upon sincere persuasion among friends. In this view, the concept of peitho serves as a proper basis for constituting both character and community. However, we have also seen that instead of privileging the ideal of peitho, the play also may be read as an endorsement of

193. W. Booth, supra note 66 , at 148.

194. See generally Sherwin, supra note 4.

195. See Cornell, supra note 191, at 1628:

When we interpret, we posit the very ideal we purportedly find "there" in the legal text, and as we posit the ideal or the ethical we promise to remain true to it. Our promise of fidelity to the ethical or to the ideal is precisely what breathes life into the dead letter of the law and provides a barrier against the violence of the word.

Cf. Rubin, supra note 85, at 1893 ("The most promising discourse for standard legal scholarship, therefore, is not the vaguely articulated neo-formalism of the courts, but prescriptive arguments based on consciously acknowledged normative positions.").

196. See Sherwin, supra note 4 , at $824-47$. 
piety: the need for mortals to submit to the will of the gods. The latter reading subverts the one White recommends. For if divine necessity compels mortal submission, what good is sincere persuasion? Mortals err. Their best intentions may be marred by pathology, unwitting error, bias, or the urge to dominate others.

But the introduction of suspicion - the earmark of modernity takes us even further than this. It subverts the second reading as well. For we moderns are led to ask by what cultural consensus can we make sense of (much less abide by) Sophocles' charge to trust in the gods, to surrender to fate? Thus, if suspicion initially undoes White's interpretive emphasis upon peitho, an interpretive emphasis upon piety falls by a similar stroke. For we must ask, is it not Sophocles himself who designed the divine intervention by which we are to be taken in? Is it not a mortal who would bespeak the immortal scheme, relying on the instruments of theater? Whereas divine command undermines the idea of mortal persuasion, mortal plotting mocks the idea of divine intervention. ${ }^{197}$

Thus do we end up with paradox built upon paradox, with language in danger of collapsing upon itself. How do we ever escape the plot of narrative? How can any persuasion cleanse itself of dolos? And here a post-modern theme - familiar of late to the practitioners of textual deconstruction ${ }^{198}$ but practiced with consummate skill by such writers as Sterne, ${ }^{199}$ Stendahl, ${ }^{200}$ and Flaubert ${ }^{201}$ in their time may be heard anew.

But deconstruction is not the goal here. Quite the contrary, the question we must face is this: How do we build up the character of inherited legal texts and institutions? How do we establish a moral universe without undue coercion, or communicative distortion, or domination? One approach requires that we articulate with heightened critical reflection the ways in which dialogic reciprocity may be created and maintained within the legal system. A major component of this approach is the intra-judicial institution of checks and balances among the discrete legal dialects which operate within the judicial branch of government.

With this approach in mind, I propose that we look at Sophocles'

197. See P. PuccI, supra note 107.

198. See, for example, the works of Roland Barthes, Michael Foucault and Jacques Derrida.

199. See, e.g., L. Sterne, The Life and Opinions of Tristam Shandy, Gentleman (Oxford Univ. ed. 1983).

200. See, e.g., Stendahl, THE Red AND THE Black, supra note 159.

201. See, e.g., G. Flaubert, Sentimental Education (R. Baldick trans. 1964). 
text yet again, this time from a third perspective - a perspective informed and motivated by the concerns expressed above.

Absent the kind of cultural consensus that permits us seriously to consider divine intervention as an acceptable means of resolving human controversy, let us substitute for Heracles a more familiar character. Let us suppose that Philoctetes, Neoptolemus and Odysseus resolve to take their dispute before not a god, or even some Herculean mortal, ${ }^{202}$ but rather a quite human arbiter, a person known for her prudent judgment. What would she say of the matter presented? What voice of authority would she empower to resolve their dispute, and to what normative consequences would her discursive choice lead?

As a matter of pure institutional power, the arbiter might seek to command compliance, favoring a particular party for no express reason or principle. ${ }^{203}$ Thus, she might simply order Philoctetes to fight for the Achaeans. Or, alternatively, she might order Odysseus to return to the plains of war without Philoctetes or his god-given bow. However, to act in this way as a matter of general practice would inevitably promote widespread unpredictability and instability, due to the impossibility of predicting the arbiter's choice of commands. Even if arbitrary commands could be predicted, their likely inconsistency would certainly be perceived as unfair, that is, as a direct violation of the fundamental demand for equal justice. As a result, the arbiter's judgment might cease to engage the losing party's compliance. Of course, the arbiter might choose to mask her commands in deceptively worded interpretations, judgments which lay claim, albeit disingenuously, to specific rules or policies. But such deception risks exposure, especially when it yields, as it inevitably must, to future inconsistencies. Once revealed as such, judicial bad faith risks public "delegitimation" and subsequent noncompliance. Our hypothetical arbiter has good reason not to select the voice of unadulterated command.

White recommends as an alternative ordinary language, the esoteric language of common sense. But what would common sense say in the case we are considering? For Philoctetes, it dictates an intuitive truth: "I have been treated unjustly. Ordinary fairness dictates that I not be made to serve my proven enemies." For Odysseus, however, there is a different common sense: "What's past is past. Now we need you. The war cannot be won unless you give in. At a time of national emergency the niceties of diplomacy must be laid aside." As for Neoptolemus, common sense might speak this way: "Look, Philoctetes, I

202. See, e.g., R. Dworkin, supra note 2, at 239-40.

203. $C f$. J. Austin, The Province of Jurisprudence Determined 4-5 (1st ed. 1832). 
made a mistake. I was taken in by Odysseus' scheming. You know what that's like. But now I'm telling you as a friend: we need you. Before, I tricked you. But now I beseech you as a friend to join us."

If common sense yields such conflicting views, which one should the arbiter endorse? What criteria can she use? How can she justify opting for one common-sense truth over another? For that which seems "self-evident" in one view may be patent nonsense within another.

Perhaps she can escape this quagmire by shifting to the abstract level of policy. Rather than commit judgment to unprincipled or ungeneralizable common-sense preferences, which might well fluctuate from case to case, she can try a more self-reflective and systematic approach. She can expressly define at the outset abstract principles, or common interests or goals, which will consistently guide and inform her judgment from case to case. For example, generalizing from Odysseus' perspective, she might say: "It is a self-evident truth that national security is a foremost requirement of social justice. Without the guarantee of survival how can we speak of protecting social interests? We are committed to maximizing the welfare of the largest number of its citizens. For the sake of the great mass of people who are jeopardized by your failure to cooperate, Philoctetes, I must order you to go along with Odysseus."

Of course, she might also generalize from Philoctetes' perspective: "It is a self-evident truth that no greater value exists than the value we assign to every person's dignity and worth as an individual. No person may be made to serve as a means to another person's end, no matter what the stakes. We will not save the body politic at the price of even a single soul. We will not forcibly fit you, Philoctetes, into a system of interests which would deny you the right to choose of your own free will whether to fight or to remain in exile."

Again, the arbiter seems caught in a dilemma. Consistency may be gained, specific policies may be systematically followed, but which one is to be chosen? By what criteria may the arbiter opt for one conceptual system as opposed to the other? ${ }^{204}$ If common sense and systematic policymaking raise internally and mutually conflicting possibilities, each reflecting different and opposing views of human nature and the nature of social institutions, what recourse remains? To opt for a particular utility seems to ensnare Philoctetes within a

204. See A. MACINTYRE, supra note 156 , at $62-64,66-67$; see also Tushnet, supra note 90 , at 1533 ("Intuitionism may be a perfectly sensible way for each of us to arrive at our judgments so that we may seek to convince others that we are right. But intuitionism standing alone cannot tell us whose intuitions ought to prevail in the end."). 
majoritarian conventionalism. But to vouch for the autonomy and dignity of each individual seems, at least in this case, to jeopardize the very fabric of society.

To complicate matters further, knowing the particular facts of this case, and the dangers that communicative distortion pose, we see that Philoctetes' intuitive sense of fairness is suspect. There is a pathological quality to his prideful and adamant clinging to suffering when the promise of health and glory is held out to him. And for his part, while Odysseus' reliance upon Helenus' prophecy cloaks his necessitarian approach with at least some appearance of authority, we neither know whether to trust this alleged prophet (who, after all, speaks as a captive of the Achaeans and thus may be maneuvering for his own benefit) or whether Odysseus has in mind his own private best interests. Finally, while we may be sympathetic to Neoptolemus' invocation of friendship as persuasive authority, this appeal might well reflect no less a coercive maneuver than the one Odysseus designed at the outset.

Upon further reflection, however, there is another discursive possibility. Prudence seeks to reconcile the wealth of competing concerns raised by each of the foregoing approaches. ${ }^{205}$ In the face of this specific, concrete controversy, the arbiter might seek to integrate the urge to do justice in the particular case with the need to establish the right precedent within the community the parties share. Judgment now will not be a one-shot attempt to resolve this isolated dispute. It will also help to establish the character of self and of society's institutions, the very nomos of the culture from which the judgment emerges - and into which it shall return as a precedential, and therefore guiding, norm.

In this sense, the speech chosen must be curative in the particular case and therapeutic to the culture as a whole. ${ }^{206}$ That is to say, the goal of judicial discourse should be to foster civilized (or nonviolent) communication among the contending parties, and among members of the society at large. According to this view, specific decisional outcomes should serve as models of socially therapeutic discourse in general. Adequately resolving specific concrete controversies requires that each of the contending parties be heard and addressed in his or her own voice. Moreover, each must be satisfied that operative social norms have been respected. ${ }^{207}$ The prudent arbiter, therefore, must

205. See Kronman, supra note 24.

206. See generally P. LAíN ENTRALGO, supra note 148.

207. See Smith, supra note 103, at 792:

[W] hen a tortfeasor compromises the normative order, punishment is not merely vindictive, but also serves a positive, restorative purpose. Holding the violator responsible for her vio- 
take care to bring the other into a common place. She must make the other's world real by acknowledging the language he speaks. She must create a shared world by speaking the other's tongue. ${ }^{208}$

Once a common ground is established, the arbiter can then seek to introduce other possibilities of self and community. The other's nomos may then be broadened so as to accommodate previously unrealized thoughts and actions. ${ }^{209}$ Only in this way can the other's liminality begin to give way to social solidarity; only then can the other begin to find his way back into the community. Curative discourse persuasively settles disputes by repairing that part of the social fabric that has been rent. In this way, judgment assumes the trappings of a ritual in which the parties concerned, as well as the witnessing public, may actively and willingly share. ${ }^{210} \mathrm{By}$ embodying the judgment in a shared ritual, vouchsafed by good judgment and rhetorical skill, our arbiter may revitalize, or create anew, a lasting tie among the members of society. Legal ritual makes that tie strong by prompting a fresh encounter with underlying social norms. Persuasively mending the social fabric introduces a renewed collective understanding of communitas into the body politic. ${ }^{211}$ This shared understanding is the

lation restores the victim's confidence in the system of norms and reinforces the norm in question so that it can continue to provide coherence and stability to the larger community.

208. See, e.g., State v. Brecht, 138 Wis. 2d 158, 405 N.W. 2 d 718 (1987). The Brecht Court attempted this task by placing the defendant's actions in a constitutional context: "Brecht argues that the state's comments on his post-arrest silence violated his constitutional right to due process of law and against self-incrimination guaranteed under the fifth and fourteenth amendments to the United States Constitution and art. I, sec. 8, of the Wisconsin Constitution. Each stage of Brecht's silence must therefore be analyzed in a constitutional light." (emphasis added) 138 Wis. 2d at 164, 405 N.W.2d at 721; see also Crane v. Kentucky, 476 U.S. 683 (1986) (noting the long established principle that "an essential component of procedural due process is an opportunity to be heard" (citing In re Oliver, 373 U.S. 257, 273 (1948), and Graves v. Ordean, 235 U.S. 385, 394 (1914)).

209. See Burt, supra note 4, at 487-88:

Dialogic engagement provides the means to create mutual meaning on which the rule of law depends. Because this engagement is the precondition for developing the capacity for meaningful exchange, it is incoherent in principle to constrain the dialogue by limiting a priori its substantive terms or the identity of the participants. ... Equality is itself an idea with content that emerges and changes over time through the process of dialogic exchange ....

See also J. DEwEY, supra note 77, at 206 ("Communication, sharing, joint participation are the only actual ways of universalizing the moral law and end.").

210. See Ball, The Play's the Thing: An Unscientific Reflection on Courts Under the Rubric of

Theatre, 28 STAN. L. REV. 81, 108-09 (1975):

Acceptance of judicial proceedings must be voluntary, and is consequently dependent upon the perceived fairness of the courts. . . .

.... In its ceremony, its costuming, its performance, and its treatment of participants in courtrooms, it embodies the legitimate exercise of power within a given sphere. Thus judicial theater is itself a continuous way of saying, in things and acts within appointed spaces, what the law is.

(footnote omitted).

211. See id. at 110 ("Judicial theater, then, holds up a mirror to legitimate society insofar as the courtroom is the locus for trying on, trying out and proving personae juris. It images lawful 
hallmark of intersubjective communication..$^{212}$

As an example of the interpretive prudence of curative discourse, consider the following narrative by a modern arbiter confronted with the situation of Sophocles' Philoctetes:

You are right, Philoctetes, to say you have been wronged. Your resentment is understandable. You have been the victim of deceit, and no one can be expected to respond any differently to such manipulative ploys.

True, Odysseus thought he acted in the best interests of his country. Perhaps he believed that Helenus' prophecy justified any means to achieve the end it foretold. But he forgot one thing: men are not gods; they cannot command others without their consent. 213

We will not make that mistake, Philoctetes. We will not demand that you sacrifice your will to the will of the majority. We will not deny your right to decide how to act. But neither will we relinquish our duty to speak what is just. ${ }^{214}$

Listen, then, Philoctetes, and see whether there is justice in what we say. We honor your freedom to decide, but we ask you, in turn, to consider others in the same light. Let us think together about the choices that have been made, and about those that may yet be decided upon. For it is not by naked right alone that justice will be done here, but by careful reflection and prudent deliberation of the issues involved. ${ }^{215}$

political community.") (footnote omitted). See also V. TURNER, Dramas, FiELDS, AND METAPHORS 45, 49 (1974) (describing communitas as a bond uniting people over and above any social bonds or positive structure and which is particularly apparent when structural conflicts must be redressed).

212. See J. HABERMAS, supra note 28, at 59 (describing the success of a speech act in terms not only of the hearer's ability to understand the meaning of the sentence uttered but also her ability to enter into the relationship intended by the speaker).

213. These opening paragraphs introduce the notion of law's constraint upon the rage for preferred ends, or for subjective instrumental manipulation of various means to a preferred end. In addition, the arbiter seeks to establish at the outset a common space in which the opposing parties obtain official recognition - on their own terms, in their own voice. Cf. Burt, supra note 4 , at 471 ("Judicial invocation of the Constitution recurrently uses the same methods as ... . parables: converting all into needy outsiders by confounding insider and outsider and then offering hope for ultimate protection by mapping a path back inside for everyone."). See also $\mathbf{R}$. BURT, Two JEwish Justices 24 (1988) ("The judge should not only be "willing . . . to listen and to consider'; he should visibly display this willingness so that the disputants themselves would follow the judge's example in their own future dealings and be led by the judge to understand one another's perspectives.").

214. This extends the arbiter's identification with the constraints introduced above (i.e., what is true for Odysseus is also true for the arbiter). Cf. Cooper v. Aaron, 358 U.S. 1, 20 (1958) ("Our constitutional ideal of equal justice under law is thus made a living truth."); J. HARLAN, Thoughts at a Dedication: Keeping the Judicial Function in Balance, in THE Evolution OF A Judicial Philosophy 289, 291-92 (D. Shapiro ed. 1969) ("Our scheme of ordered liberty is based, like the common law, on enlightened and uniformly applied legal principle, not on ad hoc notions of what is right or wrong in a particular case.").

215. Here the arbiter signals her rejection not only of coercive instrumentalism (even if this precludes maximizing a given social utility such as collective security), but also of a counterpolicy which rests upon alternative, but equally "self-evident" claims (e.g., the a priori or "natural" rights of the individual). In lieu of such putatively axiomatic points of departure, prudent interpretation will reflectively explain and justify at the outset the norms that serve as a deci- 
Let us consider your grievance against Odysseus and think as well of the harm others will suffer without you on the plains of Troy. We believe the claim against Odysseus should not go unjudged. Nor should any wrongdoing go unpunished. What the proper judgment or penalty may be, however, can only be decided after a full hearing on the matter. Let Odysseus' conduct, and your charges against him, be assessed by a fair and open-minded jury. ${ }^{216}$ That matter, however, is not the one that is now before us. Rather, our question is this: Why should you visit your grievance against one upon those others who fight for Greece? Many on the Trojan plains are your friends and allies. They have not wronged you. Why should they suffer for Odysseus' fault? ${ }^{217}$

And think too, Philoctetes, of your self. Why must your suffering go on? It has lasted long enough. Let there be an end of it. Why not let the physicians practice their art and heal your wound? If there was a price to pay for your trespass so many years ago, surely by now you have paid it. Let it come to an end. Be well again.

And with health regained, why not also gain the glory that awaits you? Think of your name, your family, your heirs. Think as well of the consequences of your actions. Consider your comrades, Achilles and Ajax. Have you reflected upon whether today's stubbornness and passion may lead to tomorrow's guilt, when your country and your comrades fall? Think, by what are your actions to be ruled: may it be ruinous folly that now beguiles you? But your own will may yet shape these events.

In our judgment, Philoctetes, your grievance against Odysseus is just, and the harm you suffered shall not be ignored. Let that grievance proceed in accordance with law and fairness. As for the justice of your

sional source of authority. Typically, this will mean deliberate analysis of applicable texts and procedures. See, e.g., Miranda v. Arizona, 384 U.S. 436, 489-90 (1966) ("We deal in our country with rights grounded in a specific requirement of the Fifth Amendment of the Constitution, whereas other jurisdictions arrived at their conclusions on the basis of principles of justice not so specifically defined."); see generally Fletcher, Two Modes of Legal Thought, 90 YALE L.J. 970 (1981) (contrasting the German legal system's reliance upon a "ruling theory" with the common law tendency to derive various principles from case law). Judging from the current literature, those who endorse rationalist (or "theoretical") constructions of law are either of the school of economic efficiency or the opposing school of Kantian (or "deontological") rights. Each camp, however, lacks the means by which to reconcile its own.conception of right with the other's. See Sherwin, supra note 4. According to Fletcher, only "committed argument" can generate "a method for decoding the multiple messages of the case law." Fletcher, supra, at 996. See also Gewirtz, Remedies and Resistance, 92 YALE L.J. 585, 680 (1983) ("To be of the law, as opposed to philosophy and economic theory ... . one must take reality as the primary realm of activity.").

216. Cf. J.B. WhITE, HERACLEs' Bow, supra note 5, at 211 (describing the lay jury as "peculiarly competent" at the practice of blaming - a practice White places "at the center of the criminal process").

217. Here the arbiter reflects a prudent awareness of the need to gain the contestants' (in this instance, Philoctetes') compliance. See Gewirtz, supra note 215, at 587 ("The intellectual and practical problem posed in each situation is whether and how the law should adjust its remedial aspiration in the face of a resistant reality .... [R]esistance cannot be ignored."). But cf. Cover, supra note 8 , at 832 (where Cover disturbingly notes: "[ $t]$ he citizen or dissenter's constitutional interpretation cannot be less the deed than that of the state's officials. If the officials of the state realize their vision in blood, the dissenter must also either suffer or impose a parallel form of violence"). 
joining the Achaeans, for your own health as well as for the survival of your friends and allies, that is a separate affair. Let it be considered on its own merits. For our part, we will not command that you act. ${ }^{218}$ Having imposed exile and expatriation, how can we now demand your service? ${ }^{219}$ Rather, we urge you to consider whether there is wisdom in our words. We ask that you weigh with care and prudence the factors we have noted. And when you choose your act, let it be knowing and intelligent and of your own free will. ${ }^{220}$

So might a prudent arbiter speak in lieu of Heracles' command at the end of Sophocles' play. It is but one version of numerous narrative possibilities. Yet, its sequence models the curative and therapeutic aspects of judicial speech within the theoretical framework proffered

218. That is, simple force, disjoined from persuasive reasons, is ruled out: it is not a legitimate basis for judicial authority. In this exemplary way, the arbiter delegitimizes Odysseus' stratagem of exercising power through deceit. See Brandeis' famous dissent in Olmstead v. United States, 277 U.S. 438, 485 (1928), cited with approval in Miranda v. Arizona, 384 U.S. at 480:

Our Government is the potent, the omnipresent teacher. For good or for ill, it teaches the whole people by its example. Crime is contagious. If the Government becomes a lawbreaker, it breeds contempt for the law; it invites every man to become a law unto himself; it invites anarchy. To declare that in the administration of the criminal law the end justifies the means ... would bring terrible retribution. Against that pernicious doctrine, this Court should resolutely set its face.

See also Spano v. New York, 360 U.S. 315, 320-21 (1959) (noting that "in the end life and liberty can be as much endangered from illegal methods used to convict those thought to be criminals as from the actual criminals themselves"); Escobedo v. Illinois, 378 U.S. 478, 489 (1964) (" "Any system of administration which permits the prosecution to trust habitually to compulsory selfdisclosure as a source of proof must itself suffer morally thereby." ") (quoting Dean Wigmore).

219. This interpretive principle, focusing upon the meaning of forced expatriation, reflects what we moderns might describe as the Achaeans' abrogation of the social contract between them and Philoctetes. Put in explicitly Hobbesian terms: the artificial contraction of rights (from Philoctetes to the state) was nullified by the Achaeans' imposition of exile. The injustice of that breach should not be compounded by the further injustice of endorsing the breaching party's insistence upon the innocent party's performance - particularly when that performance might well carry the highest possible price, life itself. See T. HOBBES, supra note 43, at 112, 120; cf. Trop v. Dulles, 356 U.S. 86, 101-02 (1958) (invalidating a congressional act that removed citizenship status from any member of the armed forces convicted of desertion during wartime). The majority in Trop condemned Congress' attempted use of denaturalization as a punishment as "cruel and unusual" and thus barred by the eighth amendment. In the words of Chief Justice Warren: "[The act imposes] the total destruction of the individual's status in organized society. ... [T] [The expatriate has lost the right to have rights." 356 U.S. at 101-02.

Here the hypothetical arbiter reflects the classic deontological position of normative reversibility: Philoctetes cannot be asked to do what no other reasonable person would do under these circumstances. Approaching the matter from the internal viewpoint of the agent in question shows the reasonableness of Philoctetes' refusal. See J. HABERMAS, supra note 28, at 90 (describing the individual's obligation to test monologically the generalizability of applicable norms).

220. After having articulated a principle of self-constraint, whereby the arbiter deliberately binds her own authority to principled discourse, the arbiter proceeds by way of what we might call dicta to suggest a course of conduct that is consistent with a prudent consequentialist analysis. Cf. Miranda, 384 U.S. at 481, where, after having set forth certain procedural safeguards as required by the fifth amendment privilege against compelled self-incrimination (the so-called "Miranda rights"), the Court goes on to state: "The limits we have placed on the interrogation process should not constitute an undue interference with a proper system of law enforcement. As we have noted, our decision does not in any way preclude police from carrying out their traditional investigatory functions." 
above. It seeks to establish a common world in which Philoctetes may feel at home. At the outset, the arbiter speaks Philoctetes' commonsense language so that Philoctetes may recognize himself within a shared social reality. The arbiter then introduces Odysseus' contrary view into the discourse. In this manner, the arbiter makes Odysseus, too, real in language. ${ }^{221}$

With regard to comprehensive policymaking, the arbiter rejects conventional, utilitarian majoritarianism. But she similarly rejects the naked rule of a categorical right. Particularized policy preferences give way to persuasive reasoning based on interpretive principle; this reasoning takes the form of a healing or curative discourse. If it has merit, it will stand as a model of socially therapeutic speech. It strives to lead Philoctetes away from his pathological stubbornness, his willful clinging to injury. It also gives new meaning to the underlying communitas that ties people together in a shared narrative of social reality. ${ }^{222}$ Rather than compel compliance based on raw power alone, the discourse strives to narrate an overlapping consensus among the contending parties. ${ }^{223}$ By speaking to the specific needs and desires of each individual, the arbiter recognizes (and in so doing makes real) the individual's autonomy, freedom, and dignity. At the same time, the arbiter expresses her unwillingness to sanction Odysseus' unprincipled, deceitful action officially. Indeed, it is precisely her commitment to principled justification that places appropriate limits upon the state's coercive power. In this way, the arbiter fulfills her duty to explain and justify prudent judgment's reaction to the specific circumstances of this particular conflict.

What course would Philoctetes choose? We do not know. The judicial task in this case, however, is done. As to the merits of the outcome, that remains a topic befitting public debate. Impelled by the desire for meaning, constituted by and reconstituting over again desire

221. Cf. Llewellyn, The Anthropology of Criminal Guilt, in Social MEaning of Legal CONCEPTS 100, 106-10 (E. Cahn ed. 1950) (describing the "parental" attitude of the New Mexican Pueblos toward criminal offenders as compared to the "arm's length" system of criminal law which characterizes our adversary system). According to Llewellyn, rather than approach the offender as "a person quite outside," the Pueblo's goal is to reintegrate the offender into the community "of which he was and still is a part." Id. at 106, 109-10. (emphasis in original).

222. See Burt, supra note 4 , at 500 :

In all of these matters, the Court should ... offer a vision that might lead others to see themselves clearly as members of a single, interdependent, and mutually supportive community. ... The underlying goal in all cases is for the Court to ensure that anyone's claim for inclusion in a communal relation receive sustained, serious attention from all others.

See also V. TURNER, supra note 211.

223. See Rawls, supra note 52. 
as story and plot, perhaps it is the reader after all who must be the judge. ${ }^{224}$

\section{CONCLUSION}

Rhetoric describes a wide and diverse field, exceptionally fertile in our time. The importance and usefulness of this field to legal scholars and practitioners alike warrant its further study and critique. The constitutive rhetoric that White advocates represents a useful point of departure for this edifying task. Among its virtues is its power to reveal the deep complementarity between discourse and practice. In this way it also points up the centrality of ethics in all legal discourse, simultaneously expanding the need for self-reflective articulation of standards and sources of authority for judgment and the need to take direct responsibility for explaining and justifying them.225

But along with increased knowledge of the power of discourse comes an increased need for critical reflection. The dangers that attend rhetorical practice must be recognized and countered. For example, the conflicting images of common sense, like the mutually exclusive and individually totalizing concepts of comprehensive policymaking, risk different forms of discursive tyranny. Each of these discrete ways of thinking and talking gives rise to narratives that may make no sense to those who speak in a different voice. Thus, if allowed to achieve privileged status, a dominant (albeit partial) language of power in society tends to mute alternative forms of discourse.

Thus, granting that White's constitutive rhetoric offers a viable point of departure for prudent judgment, and that it exerts an important corrective influence upon abstract critical theory, there are dangers in extending his perspective too far. Rhetoric simply cannot cut theory off and then proceed to occupy the field of interpretive practice

224. While it may be true that judges maintain an official grip on the ruling "language[s] of power" in the legal culture, that power is far from absolute. The public's right to dissent still remains intact. See Cover, supra note 4 , at 1618 :

Legal interpretation may be the act of judges or citizens, legislators or presidents, draft resisters or right-to-life protesters. Each kind of interpreter speaks from a distinct institutional location. Each has a differing perspective on factual and moral implications of any given understanding of the Constitution. The understanding of each will vary as roles and moral commitments vary. But considerations of word, deed, and role will always be present

in some degree. The relationships among these three considerations are created by the prac-

tical, violent context of the practice of legal interpretation, and therefore constitute the most significant aspect of the legal interpretive process.

See also Sherwin, supra note 43, at 411 (maintaining that, contrary to H.L.A. Hart's legal positivist view that citizens need only obey valid rules of behavior, both the lay public and the legal expert "need share in the struggle for consensus on ultimate values").

225. This is what Wayne Booth calls "the art of discovering good reasons." See W. BootH, supra note 66 , at xiv. 
by itself. The dangers historically associated with such a move include not only the unchecked fecundity and polysemy of rhetorical utterance, but also rhetoric's constant vulnerability to instrumental manipulation, subjective ideology, false consciousness, and individual pathology. Each of these dangers, in its own way, promotes its own type of communicative distortion - a distortion that may be intentional or unwitting. In any event, the effect is the same: surface narrative disguises hidden meanings.

It is with these dangers in mind that this article introduces the curative notion of suspicion. By critically and self-reflectively questioning not only the story being told but also the way in which it is being constructed, the partialities of individual preference or prejudice, and the incommensurability of submerged concepts and metaphors, may be recognized and critically assessed. Suspicion targets both the text and the reader. In this way, it makes plain both the need to give reasons which explain and justify interpreting or creating particular types of narrative, and the need to provide justifications for choosing one discursive characterization of facts and norms as opposed to another, or one normative conceptual schema or model as opposed to another. Thus critical reflection expands the range of discourse to include the prejudices and discrete tyrannies to which legal rhetoric is susceptible. The safeguarding method of instituting checks and balances among discrete legal dialects exemplifies the kind of dialogic analysis that such critical reflection makes possible.

Contrary to White's suggestion, it will not do to abandon theory, confident in the belief that the contextual richness of ordinary language will suffice as a guide and source of directives for interpretive practice. Once subjected to critical reflection, the unreflective truths and imperial metaphors of ordinary common sense and legal interpretation may appear too conflicting and too dubious. Nor is it enough to succumb to the philosopher's or policymaker's urge to idealize reality by elevating ordinary language to the abstract level of concept formation. Endorsing a particular comprehensive view, based upon axiomatic truths or privileged principles, imposes upon others a narrative reality subject to the distortions of any partial discourse.

If we are to escape the related dangers of dialogic tyranny and communicative distortion, I believe we must come to understand better the characteristic virtues and defects of each type of discourse in the context in which it is being used. This mandates dialogic heterogeneity, since any single form of discourse may be inappropriate or inadequate to do justice within a given context.

Leaving a particular dialect's defects unchecked is an invitation to 
tyranny. To avoid such an eventuality, I have introduced the notion of an intra-judicial institution of checks and balances among diverse forms of legal voice. This dialogic interaction checks and balances the discrete limitations of a particular discourse with the virtues of another. I have suggested that it is one of the virtues of prudent interpretation to provide the dialogic space in which this discursive interaction and accommodation can take place.

Finally, shifting our focus from institutional analysis to theory, the notion of checks and balances serves yet another function. With the advent of suspicion, White's desirable (albeit idealized) model of constitutive rhetoric may be checked and balanced by a more realistic assessment of critical theory, and of the role that regulative concepts and heuristic theoretical models have to play within the legal culture.

Having thus laid the groundwork for legitimate interpretive practice, we stand ready to follow the path that White's rhetoric lays open. Along that way, judges, lawyers, and scholars can begin to build up where others have taken down. 